\title{
El diccionario, fuente para la historia del léxico: la supresión de arcaísmos gráficos en la sexta edición del Diccionario de la lengua castellana de la Real Academia Española (1822)
}

\author{
Enrique Jiménez Ríos ${ }^{1}$ \\ Universidad de Salamanca, España
}

\begin{abstract}
Resumen
El artículo estudia los arcaísmos gráficos contenidos en el Diccionario de la lengua castellana de la Real Academia Española. Para ello se toma la sexta edición, que destaca por abordar el tratamiento de este tipo de formas. Se señalan los cambios efectuados en el paso de la quinta a la sexta edición y su situación en ediciones anteriores y posteriores, así como las razones que llevan a su producción en ese momento; se analiza la naturaleza de los arcaísmos gráficos eliminados (características, tipología, fecha de aparición en la lengua y en el diccionario, documentación textual, etc.), al lado de otras variantes gráficas arcaicas mantenidas; y se extraen las consecuencias de esta decisión académica para el conocimiento de la historia del léxico. Se concluye que con esta supresión la Academia moderniza el diccionario y avanza en su consideración como obra destinada a ofrecer la lengua usual, pero también se pierde una información relativa a la historia del léxico, propia del diccionario como obra didáctica.
\end{abstract}

Palabras clave: arcaísmo, grafía, diccionario, Real Academia Española.

\footnotetext{
Para correspondencia, dirigirse a: Enrique Jiménez Ríos (enrique@usa.es), Departamento de Lengua Española. Facultad de Filología. Universidad de Salamanca. Plaza de Anaya, 1. 37008 Salamanca, España. Telf. +34 923294445 ext. 1739.
} 
THE DICTIONARY, A SOURCE FOR THE HISTORY OF LEXICON: THE SUPPRESSION OF GRAPHICAL ARCHAISMS IN THE SIXTH EDITION OF THE DicCIONARIO DE LA LENGUA CASTELLANA BY THE ROYAL SPANISH ACADEMY (1822)

\begin{abstract}
This article studies the graphic archaisms in the Diccionario de la lengua castellana of the Spanish Royal Academy. To do so we study the sixth edition, which stands out for addressing these types of forms. The changes made from the fifth to the sixth edition and their situation in earlier and later editions are broached, as well as the reasons that led them to take place at that time. The nature of the graphic archaisms eliminated is also analysed (characteristics, typology, date it appeared in the language and in the dictionary, textual documentation, etc.) and compared to the other graphic archaisms that were maintained in the dictionary. The impact of this decision by the Academy for the history of the language is then addressed. It is concluded that with this suppression the Academy modernized the dictionary and made progress towards its being considered a work destined to offer the language in use; however, at the same time we have lost information relating to the history of the words, which would be typical of the dictionary as a didactic work.
\end{abstract}

Keywords: archaism, spelling, dictionary, Spanish Royal Academy.

Recibido: 30/08/17

Aceptado: 30/04/18

\title{
1. JUSTIFICACIÓN ${ }^{2}$
}

Las primeras palabras de este artículo van dirigidas a justificar su título. Con él se quiere destacar la función del diccionario como fuente de información léxica y, en concreto, el papel que desempeñan los arcaísmos gráficos para conocer la historia del léxico, pues se recogen estas formas existentes en otro

2 Este artículo se enmarca en el proyecto de investigación "Historia interna del Diccionario de la Lengua Castellana de la RAE en el siglo XIX (1817-1852)" (FFI2014-51904-P), del Ministerio de Economía y Competitividad del Gobierno de España. Agradezco a Gloria Clavería, investigadora principal de este proyecto, las observaciones y correcciones hechas a este trabajo. 
momento de la historia de la lengua al lado de las que las han sustituido. Los diccionarios, además de ser una herramienta para el usuario de la lengua, son una fuente de información para el investigador, algo muy claro cuando se trata de diccionarios del pasado o de ediciones pasadas de un mismo diccionario, como sucede con el Diccionario de la lengua, castellana, primero, y española, después, de la Real Academia Española. La información recogida en cada edición, las adiciones, supresiones y enmiendas que se producen, revelan cómo es la lengua, cómo es la sociedad que la habla, pero también qué presupuestos teóricos subyacen a la confección de la obra y qué ideas lingüísticas la determinan, estableciendo vínculos con la tradición o dando muestras de renovación y cambio. Por eso, que el diccionario académico recoja arcaísmos gráficos, y que en la sexta edición los elimine, tiene una explicación en estos hechos, en particular, en la renovación de la obra, pues su actualización lleva a esta supresión, así como en el tipo de diccionario, que hace que no se consideren propias de un diccionario como el académico estas variantes (aunque sí otro tipo de arcaísmos). Con todo, su presencia en la obra, que en ediciones anteriores se promoviera su inclusión, que unas formas sean eliminadas y otras mantenidas, y que la correspondencia con las formas que las sustituyen sea explicable por cambios en la articulación y en la pronunciación, interpretados como fases de la evolución histórica de la palabra, o como incorrecciones y transgresiones, merece ser destacado, por lo que tiene de interés para el conocimiento de la historia del léxico ${ }^{3}$.

\section{INTRODUCCIÓN}

Los diccionarios generales recogen variantes formales, muchas de ellas arcaísmos (Haensch 1985: 235; Castillo Peña 1992: 537; Haensch y Omeñaca 2002: 195, 207; Castillo Carballo 2003: 84; Clavería 2018: 43-44)4. En el de la Real Academia Española esto se ve con claridad, pues son muchas las variantes arcaicas registradas, de distinto tipo, gráficas, morfológicas y

\footnotetext{
3 Vid. el reconocimiento de la variación en la pronunciación expuesto ya por la Real Academia Española en el Discurso proemial de la orthographia (Discurso: LXVII-LXVIII).

4 Esto es general en todos los diccionarios y lo es como consecuencia de la existencia de la variación léxica, dialectal, social y de registro. Luego, la idea de que hay que conservar la lengua del pasado y de que esto ha de hacerlo el diccionario, justifica la inserción y mantenimiento de arcaísmos.
} 
léxicas ${ }^{5}$ (Haensch et al. 1982: 456; Castillo Peña 1992: 541; Jiménez Ríos 2001: 266), y en su incorporación y eliminación destacan algunas ediciones (Clavería et al. 2017; Clavería 2018: 42). Las gráficas se caracterizan por diferencias en la grafía de la palabra y por remitir, como las morfológicas y léxicas, a otra forma, que es la recomendada, la mejor o, sencillamente, la que está en uso (Lázaro 1972 [1980]: 106; Castillo Peña 1992: 534; Alcoba 2007: 13-14; Carriscondo 2009: 109; Quilis Merín 2009: 96; Muñoz 2018: 211).

La variación, alteración y cambio gráfico que presentan estas variantes gráficas afectan a vocales y consonantes (Lapesa 1986: 207). Los cambios vocálicos se producen en vocales átonas, básicamente, aunque puede haber algún caso de vocal acentuada ( $c f$. mesmo), y los consonánticos en consonantes implosivas y grupos consonánticos, preferentemente, aunque los hay también en consonantes en posición inicial, en posición interior intervocálica y en inicio de sílaba tras consonante. Tanto unos como otros resultan de cambios gráficos, consecuencia de diferencias gráficas (dapno/ daño, inremediable/irremediable), o de cambios en la articulación de la palabra, que en unos casos reflejan fases de su evolución histórica (fuertal huerta, acaescer/acaecer, eficace/eficaz) y en otros resultan de transgresiones e incorrecciones en su pronunciación (cativar/cautivar, probe/pobre) ${ }^{6}$. Esta distinción determina la suerte de estas formas en el diccionario con su supresión o mantenimiento, en lo que influye, además, la existencia de remisión o definición en su explicación (Jiménez Ríos 2018: 409; Muñoz 2018: 217-218).

El objetivo de este trabajo es estudiar la suerte de los arcaísmos gráficos contenidos en el diccionario académico. Por arcaísmo gráfico se entiende aquella voz desusada cuya diferencia con la usual que la ha sustituido está en una de las grafías que la forman. Para ello se parte de la sexta edición, que destaca por abordar el tratamiento de este tipo de formas (DRAE 1822: Prólogo; Alvar Ezquerra 2002: 268; Alcoba 2007: 14; García Santos 2011:

5 Castillo Peña (1992: 536-537) observa que en el diccionario académico hay una preferencia por que el lexema que remite tenga la marca de anticuado y el $55 \%$ de esos casos son variantes morfológicas. Por su parte, Muñoz (2018: 211) hace una adecuada distinción entre variantes gráficas, morfológicas y léxicas: las gráficas son aquellas que varían en sus grafías; las morfológicas, aquellas palabras que, compartiendo la misma raíz, presentan diferencias en los otros elementos que las forman; y las léxicas, las que no se ajustan a las dos distinciones que se acaban de señalar. Por ello, no es fácil determinar, sin un cómputo de formas, cuál de las tres es la más abundante, pues esto ha de estar determinado por el tipo de diccionario y, por tanto, por la tendencia a registrar formas del pasado, variantes formales, etc.

${ }^{6}$ Vid. sobre este asunto el parágrafo "Causa de la variedad y confusión de la Orthographia...” (Discurso: LXVIII-LXX). 
457). Se trata, entonces, 1) de señalar los cambios efectuados en el paso de la quinta a la sexta edición del diccionario y su situación en ediciones posteriores ${ }^{7}$, además de las razones que llevan a su producción en ese momento $^{8} ; 2$ ) de analizar la naturaleza de los arcaísmos gráficos eliminados (características, tipología, fecha de aparición en la lengua y en el diccionario, documentación textual, etc.), al lado de otras variantes gráficas arcaicas mantenidas; y 3) de extraer las consecuencias de esta decisión académica tanto para la historia de la lengua como del léxico y del diccionario.

\section{EL TRATAMIENTO DE LOS ARCAÍSMOS GRÁFICOS EN LAS OBRAS ACADÉMICAS}

\subsection{El PRÓlogo DE LA SEXTA EDICIÓN DEL DicCIONARIO}

En el prólogo de la sexta edición, publicada en 1822, se trata, por primera vez, de la supresión de voces (en la anterior ya se reformaron y eliminaron algunas, las fácilmente formables, algunos arcaísmos y voces de uso metafórico o pasajero, por ejemplo) (DRAE 1817: Prólogo; Clavería 2016: 88-89; Jiménez Ríos 2018: 399; Muñoz 2018: 207). En esta ocasión, el deseo de que las adiciones no aumenten el volumen del diccionario lleva a suprimir fórmulas y artículos: "Y para no hacerla mas embarazosa con el aumento de voces, que tenia reunidas, acordó la supresión de algunas fórmulas y artículos que creyó podrian excusarse sin perjuicio de la claridad conveniente y con mucho ahorro de palabras" (DRAE 1822: Prólogo).

Las fórmulas son las que preceden a la remisión ${ }^{9}$ y los artículos que se pueden excusar, los que presentan variación gráfica:

\footnotetext{
7 La mirada a lo que sucede en ediciones posteriores es interesante, pues unas voces se eliminan en el paso de la quinta a la sexta edición, otras se mantienen, y otras, a pesar de eliminarse entonces, vuelven más tarde al diccionario. $1820)$.

9 "Asi es que ha omitido en las voces sinónimas ó de un significado la fórmula Lo mismo que, poniendo en versalillas la voz correspondiente mas castiza ó de un uso más general" (DRAE 1822: Prólogo). Sobre el uso de esta fórmula en la quinta edición, vid. Muñoz (2018: 205).
} 
Tambien ha prestado motivo para la supresion ó reforma de muchos artículos la razon de que los diversos estados de pronunciación y ortografía que padece una voz desde que sale de una lengua madre, de la latina por ejemplo, hasta que se fija en un idioma vulgar como el castellano, no deben mirarse como palabras diversas (DRAE 1822: Prólogo).

Expresa así la Academia la intención de suprimir aquellas variantes gráficas que reflejan, sobre todo, cambios en la pronunciación y muestran fases de la evolución histórica de una palabra (Menéndez Pidal 1987: 66; Cano 1988 [2002]: 70, 109; Ariza 1999: 59, 69, Alcoba 2007: 31). Estas variantes, que no deben mirarse como palabras diversas, resultan de "la alteración que con los tiempos sufren las letras de un mismo órgano como la $e$ y la $i$, la $o$ y la $u$, la $b$ y la $p$, la $t$ y la $d$ y así otras" (DRAE 1822: Prólogo) ${ }^{10}$, fenómeno al que se añaden otros como "la torpe pronunciación de la gente rústica por el vicio contraído, y aun casi peculiar de algunas provincias", y "la corrupción de los tiempos del mal gusto y de la decadencia de las letras" (DRAE 1822: Prólogo), lo que supone dirigir, además, la atención a cambios gráficos que reflejan cambios en la pronunciación por "transgresión", "corrupción" o "vicio" (Alcoba 2007: 31). Como ya se apuntaba en el Diccionario de autoridades, "estas alteraciones viciosas, que tanto han perjudicado [y que lo siguen haciendo, otras similares, al menos desde la postura normativa de la Academia] a la pureza y fijación del idioma castellano vienen desde muy antiguo" (Autoridades 1726-1739: XXIII; Clavería 2016: 92), pues "se quejaba el autor del Diálogo de las Lenguas de que se dijese arbor por árbol, resolgar por resollar, rancor, rabaño por rencor y rebaño, y levar por llevar, espera por esfera y así otros vocablos" (DRAE 1822: Prólogo) ${ }^{11}$. Afirman los académicos que el autor del Diálogo lo atribuía a "inadvertencia" más que a "deliberación" (como haría hoy cualquier lingüista que quisiera explicar la razón de ser de una incorrección); los escritores de entonces quieren "pulir y suavizar las voces", pero la decadencia del buen gusto derivó en "afectar latinidad” ( $c f$. González Ollé 1992: 166, 175, 184 y 190) ${ }^{12}$ y, con ella, en

10 Otras como las citadas a continuación, relativas a grupos consonánticos, palatales, etc., y como las palabras con grafía de doble $s$, a que la Academia ya se había referido en su Ortografía de 1763 (ORAE 1820: XI).

11 “Aunque árbor es más latino, tengo por mejor dezir árbol” (Barbolani 1995: 176); “me contenta más resollar que resolgar" (Barbolani 1995: 177); "Yo por mejor tengo dezir llevar, aunque no fuesse sino porque levar también sinifica 'levantar"' (Barbolani 1995: 177).

${ }_{12}$ La duplicación de letras se mantuvo con rigor en lo antiguo; en el siglo XVI empezó a producirse un cambio, admitido por unos y rechazado por otros (Discurso: LXXV). 
el surgimiento de dobletes neolatinos (Alcoba 2007: 31). El resultado fue la multiplicación de formas con el mismo origen y significado-asumpto/ asunto (lat. assumptus), presumpto/presunto (lat. praesumptus), escripto/ escrito (lat. scriptus), al lado de coluna/columna (lat. columna), afeto/ afecto (lat. affectus, - $a$, -um), repunar/repugnar (lat. repugnāre), ecelentel excelente (lat. excellens, -entis)-, que no merecen artículos separados en el diccionario. Precisamente a esta misma situación de variantes formales, hoy, y de cambios gráficos ocasionados por diferencias prosódicas, por "transgresión" o "corrupción", según se ve en los textos que se acaban de leer de la Academia, se refiere Menéndez Pidal (1987: 67) al tratar de hechos relativos a la evolución gráfico-fonética de la lengua:

Aun es más: fuera del acento, las mismas dos vocales tan diversas palatales, $e, i$, o las dos velares $o, u$, no difieren entre sí tanto como cuando van acentuadas. Esto permitía, aun el siglo XVI, vacilaciones en el lenguaje literario, que no eran posibles respecto de las vocales acentuadas; así estaban admitidas en el habla culta vanedad, envernar, escrebir, abondar, roido, rofián, cobrir, si bien las formas actuales ya prevalecían en personas de mejor gusto, como, por ejemplo, Juan de Valdés, que desecha las variedades apuntadas ${ }^{13}$.

Por último, se advierte en este prólogo que se ha procurado suprimir solo aquellas voces cuyo significado se comprende con facilidad y cuya composición y carácter se ha conservado en las que las han sustituido (Clavería 2016: 88). Es decir, que se mantienen aquellas en las que no se dan estas características. Por tanto, hay formas que se suprimen y formas que se mantienen; formas que responden a cambios en la pronunciación y el uso, que reflejan la evolución de la lengua o muestran su transgresión e incorrección, y formas que obedecen a cambios meramente gráficos. El examen de ejemplos concretos revela comportamientos distintos en el diccionario en fenómenos similares.

13 En el Diálogo, la postura de Valdés es la siguiente: “M. En estos vocablos que diré, como son abundar o abondar, rufián o rofián, ruido o roído, cubrir o cobrir, jaula o jáola, tullido o tollido, riguroso o rigoroso, ¿quál tenéis por mejor, la $o$ o la $u$ ? $-\mathrm{V}$. En todos éssos yo siempre scrivo la $u$, porque la tengo por mejor; creo hazen assí los más" (Barbolani 1995: 165-166). 


\subsection{OBRAS ORTOGRÁFICAS Y LEXICOGRÁFICAS ANTERIORES A 1822}

Con anterioridad a lo expuesto en esta edición, la Academia se había referido a la ortografía de las palabras y a los cambios por ella experimentados en el Discurso proemial de la orthographia de la lengua castellana, contenido en las páginas preliminares del Diccionario de autoridades (Discurso: LXI-LXXXIV; Rosenblat 1951: LXIV; Esteve 1982: 60; Freixas 2016: 113; Blanco 2018: 57). Ahí aparecen ya expuestos los tres criterios que han determinado la ortografía de una palabra: etimología, pronunciación y uso (Discurso: LXI; ORAE 1820: 2; Esteve 1982: 69; Alcoba 2007: 16; Terrón 2018: 68-70), si bien con el tiempo la pronunciación se convierte en modelo académico, sin abandonar el recurso a los otros dos (Lázaro 1972 [1980]: 107; García Santos 2011: 465-466; Martínez Alcalde 2012: 101). Y así se mantendrá al publicarse la Ortografía en 1815 (García Santos 2011: 471, 477), en que el objetivo es "simplificar mas y mas la escritura" y "rectificar la pronunciación" (ORAE 1815: XIV), que "se debe tener por regla única y universal" (apud Terrón 2018: 70; Quilis Merín 2009: 96). En la edición siguiente de la Ortografia, la novena de 1820, más cercana al diccionario que nos ocupa y reimpresión de la de $1815^{14}$, se ahonda en el uso como "árbitro de la lengua" (ORAE 1820: III-IV), pues la pronunciación puede variar de unos hablantes a otros, de lo que puede colegirse que se considera perteneciente a la esfera de lo individual, mientras que el uso es de la colectividad, de los eruditos (Esteve 1982: 70-71). Con todo, el cambio en la consideración de los criterios para fijar la ortografía de una palabra ya se había efectuado, y lo había hecho desde mediados del siglo XVIII, pues del criterio etimológico se había pasado a fijar la atención en el uso, un uso para el que ya no tendría sentido registrar en el diccionario estas variante gráficas arcaicas, a menos que su inclusión y conservación obedeciera a otros motivos ${ }^{15}$.

Tras la publicación de Autoridades y de ese discurso, hay referencias a la ortografía en la segunda edición de aquel diccionario para advertir de que las autoridades de las voces anticuadas se consignan con la ortografía que presentan las obras de las que se extraen:

14 Se trata de una reimpresión, repetida en 1826, de la de 1815 (García Santos 2011: 472, nota 47, y 477$)$.

15 En la primera edición de la Ortografía, de 1741, se acuerda eliminar grafías arcaicas como sciencia por ciencia o specie por especie, aunque la reducción no afecta a otras grafías que pueden considerarse del mismo tipo, como ph, rh, th o ss. (García Santos 2011: 466, 468). 
Las autoridades de voces antiquadas se ponen con la misma ortografía que tienen en las obras e impresiones de que se tomaron: y quando hay tal variedad que no puede resolverse por el uso antiguo, se ponen conforme á la Ortografía de la Academia. Pero las autoridades de voces del uso corriente se escriben siempre con arreglo á esta, porque la variedad que en ellas se halla suele depender de los impresores ó de un uso arbitrario y no de algún particular sistema de los autores (Autoridades 1770: IX).

Declaración importante, pues determina que la forma de la palabra que presentan los textos aparezca en el diccionario y, por tanto, que se recojan variantes gráficas arcaicas reveladoras de la evolución histórica de una palabra ${ }^{16}$. Se hacía, además, esta afirmación en un diccionario caracterizado por recoger de manera particular los arcaísmos (Autoridades 1770: V). A partir de ahí, las referencias a la ortografía que hace la Academia resultan de las ediciones que publicó la corporación de esta otra obra normativa ${ }^{17}$ : los cambios anunciados tratan de la distinta representación gráfica de un sonido y de las diferencias en la prosodia de una palabra con repercusión gráfica, que es lo que se aborda por primera vez en la sexta edición del diccionario académico ${ }^{18}$.

Ciertamente, una cosa es el modo de escribir una palabra y otra que esta refleje la escritura de otra época o los "errores y defectos" en su pronunciación. En este momento, la nueva ortografía y la reforma ortográfica que la sustenta determinan la supresión del diccionario de variantes gráficas, reflejo de estadios anteriores de la lengua y de transgresiones en la pronunciación (Alcoba 2007: 49), lo que es positivo en el primer caso, por lo que tiene de muestra de modernidad el abandono de formas del pasado, pero negativo en el segundo, el de suprimir incorrecciones, si con ello se pierde una información relativa al papel correctivo y normativo ejercido

16 Más tarde, en la Ortografía de 1820 se afirma que "las voces antiguas experimentaron también su mudanza, por haberse alterado su pronunciación y escritura: efectos que proceden de la mezcla de unos lenguages con otros, y de la libertad y variedad del uso" (ORAE 1820: I-II).

17 La $5^{\mathrm{a}}$ edición, de 1775 , la $6^{\mathrm{a}}$, de 1779 y la $7^{\mathrm{a}}$, de 1792 . En el prólogo de la cuarta edición del diccionario, de 1803 , se señalan los cambios de las grafías $c h$ y $l l$, el valor de la grafía $c h$, cuando no representa un sonido dental (ORAE 1820: XII, 14 y 28), y la sustitución de $p h$ por $f$; en la quinta, de 1817, dos años después de publicada la octava edición de la Ortografía académica, es obligada la referencia a esta obra: "Hubiera sido inconsecuencia inexcusable el que la Academia no siguiese con puntualidad en su Diccionario las reglas que tiene prescritas en su tratado de Ortografía" (DRAE 1817: Prólogo).

18 Se había tratado de ello en la Ortografía de 1820 al señalar que "para hacer mas dulce y suave la pronunciación, suprimió o sustituyó algunas consonantes en las voces en que ya el uso iba indicando esta novedad" (ORAE 1820: XIII). 
siempre por la corporación académica (García de la Concha 2014: 99). Se habían mantenido estas variantes por apego a la lengua del pasado y, si habían sido incorporadas, lo habían hecho también por esta misma razón (Clavería 2018: 45-46; Muñoz 2018: 214, 217); la evolución, entendida como modernización, favorece su supresión, pero también el mantenimiento, e incluso, su reincorporación, si lo que se pretende es destacar el carácter didáctico del diccionario y con ello que no se pierda el conocimiento de esas formas del pasado.

\section{ORIGEN Y EVOLUCIÓN DE LOS ARCAÍSMOS GRÁFICOS DEL DICCIONARIO}

Se ha dicho más arriba que los cambios gráficos responden, sobre todo, a cambios fonéticos, los cuales, promovidos por el uso, resultan de cambios en la articulación y en la pronunciación, y pueden llegar a ilustrar fases de la evolución histórica de una palabra, o ser, simplemente, muestras de incorrección o transgresión. Para ejemplificar esta situación, en este trabajo se parte de un corpus formado por una muestra representativa de todas las letras del diccionario: como mínimo de la primera combinación de letras de todas las letras del diccionario, si ello permite contar con datos suficientes para cada una de ellas ${ }^{19}$. Se han extraído todas las palabras, variantes gráficas arcaicas de cada combinación, pero en el curso de la exposición solo se explican algunos ejemplos de distintas letras, en particular familias o grupos morfológicos participantes de los mismos cambios vocálicos y consonánticos. Los siguientes apartados en que se exponen estos ejemplos están organizados atendiendo a los cambios vocálicos y consonánticos que se reflejan en la ortografía de las palabras, a la supresión o mantenimiento de

19 En algunas letras, dada la corta extensión de la primera combinación, se ha ampliado la consulta. Estas son las combinaciones, no incluida aquella a la que llega, y las páginas consultadas en cada letra (según la paginación de la edición en el NTLLE disponible en www. rae.es): A-ACA (páginas 1.1-8.1), B-BE (páginas 112.1-125.1), C-CE (páginas 149.1-191.1), D-DI (páginas 274.1-295.1), E-EN (páginas 339.1-350.3), F-FE (páginas 407.1-412.3), G-GI (páginas 431-1-442.3), H-HI (páginas 457.1-467.2), I-IN (páginas 482.1-487.2), J-JU (páginas 504.1-508.1), L-LE (páginas 512.1-520.3), M-ME (páginas 540.1-562.3), N-NO (páginas 592.1-600.1), O-OJ (páginas 605.1-612.1), P-PE (páginas 624.1-650.3), Q (páginas 719-723.1), R-RE (páginas 723.1-731.1), S-SE (páginas 775.1-789.2), T-TE (páginas 823.1832.1), U (páginas 869.1-874.1), V-VI (páginas 874.1-889.1), X (páginas 902.1-903.1), Y (páginas 903.1-905.1) y Z (páginas 905.1-912.3). 
dichas palabras en el diccionario, y al tipo de cambio producido. Muestran la importancia que en todo ello tiene el $D R A E 1822$ y seguirán teniendo ediciones posteriores, pues "durante la primera mitad del siglo XIX el diccionario es un campo de ensayo de las innovaciones ortográficas" (Quilis Merín 2009: 97).

\subsection{ArCaísmos gráficos CON CAMBios VOCÁLICOS}

En el corpus confeccionado y en los ejemplos seleccionados hay palabras, arcaísmos gráficos, cuya diferencia con las correspondientes usuales es la existencia de cambios vocálicos que afectan a vocales átonas, en posición inicial, interior o final de palabra.

\subsubsection{Supresión}

4.1.1.1. En posición inicial, las voces eguado, egual, egualado, egualamiento, egualanza, egualar, egualdad [1] ${ }^{20}$, egualdad [2], egualeza, egualidad y egualmente, además de las expresiones a la eguala y por egual, ilustran esta situación de supresión de arcaísmos gráficos del diccionario, pues todas se eliminan en la sexta edición, de 1822:

\begin{tabular}{|l|l|l|}
\hline \multicolumn{1}{|c|}{ Posición inicial } & \multicolumn{1}{|c|}{ DRAE 1817 } & DRAE 1822 \\
\hline EGUADO* & ant. Lo mismo que IGUAL & $\varnothing$ \\
EGUAL & ant. Lo mismo que IGUAL & \\
EGUALADO & p.p. de EGUALAR & \\
EGUALAMIENTO & ant. Lo mismo que IGUALAMIENTO & \\
EGUALANZA* & ant. Lo mismo que IGUALDAD & \\
EGUALAR & ant. Lo mismo que IGUALAR & \\
EGUALDAD [1] & ant. Lo mismo que IGUALDAD & \\
EGUALDAD [2]* & ant. Lo mismo que EQUIDAD* & \\
EGUALEZA* & ant. Lo mismo que IGUALDAD & \\
EGUALIDAD* & ant. Lo mismo que IGUALDAD & \\
EGUALMENTE & ant. Lo mismo que IGUALMENTE & \\
A LA EGUALA & ant. Lo mismo que AL EGUAL & \\
POR EGUAL & ant. Lo mismo que AL IGUAL & \\
\hline
\end{tabular}


Todas estas voces, reveladoras de cambios en la pronunciación de las palabras (lat. aequālis) ${ }^{21}$, habían sido introducidas en la tercera edición, de 1791; en ellas, la presencia de eguado, egualanza, egualdad [2], egualeza y egualidad obedece al deseo de recoger arcaísmos, no solo gráficos, si se atiende a las características de estas palabras que remiten a una variante morfológica y no gráfica:

EGUADO adj. ant. Lo mismo que IGUAL

EGUALANZA. s. f. ant. Lo mismo que IGUALDAD (cf. igualanza)

EGUALDAD [2] s. f. ant. Lo mismo que EQUIDAD

EGUALEZA. s. f. ant. Lo mismo que IGUALDAD ( $c f$. igualeza)

EGUALIDAD s. f. ant. Lo mismo que IGUALDAD ( $c f$. igualiad)

En la edición siguiente a aquella en que fue incorporada la serie, la cuarta, de 1803, se introdujeron los arcaísmos igualanza, igualeza e igualidad:

IGUALANZA. s. f. ant. Lo mismo que IGUALDAD

IGUALEZA. s. f. ant. Lo mismo que IGUALDAD, CONFORMIDAD

IGUALIDAD. s. f. ant. Lo mismo que IGUALDAD

No cambiaron con su remisión a ellos las voces egualanza, egualeza y egualidad, por no remitir de un arcaísmo a otro. La existencia de aquellas formas -igualanza, igualeza, igualidad- corrobora, además, la condición de arcaísmos gráficos de estas - egualanza, egualeza, egualidad-, a pesar de que no remiten a ellas en su explicación en el diccionario.

Asimismo, la documentación textual de egualeza/igualeza, egualanza/ igualanza, similar en el CORDE tanto en presencia como en fechas de aparición -algo que los datos del $\mathrm{CDH}$ parecen confirmar (consulta 8.2.2017)-, y la irrelevancia documental en estos dos corpus de las variantes egualidad/igualidad, hace que en los primeros ejemplos la razón para su eliminación sea su carácter gráfico y en el último, además, su escasa documentación:

21 Egual, forma antigua con respecto a igual, si bien en manuscritos antiguos se encuentra también igual. Hasta el siglo XV alternan las dos formas, pues la generalización con $i$ se produce a partir de Nebrija (DECH, s. v. igual). 


\begin{tabular}{|c|c|c|c|c|}
\hline Palabra & \multicolumn{2}{|c|}{ CORDE } & \multicolumn{2}{|c|}{$\mathrm{CDH}$} \\
\hline EGUALEZA & 16 casos en 14 doc. & s. XIII-XV & 19 casos & $\begin{array}{l}\text { s. XI-XV (18) } \\
\text { s. XVI (1) }\end{array}$ \\
\hline IGUALEZA & 20 casos en 13 doc. & s. XIV-XVI & $\begin{array}{l}43 \text { casos en } 32 \\
\text { doc. }\end{array}$ & $\begin{array}{l}\text { s. XI-XV (38) } \\
\text { s. XVI (4) } \\
\text { s. XIX (1) } \\
\end{array}$ \\
\hline ygualeza & 21 casos en 19 doc. & s. XIV-XV & $\begin{array}{l}21 \text { casos en } 19 \\
\text { doc. }\end{array}$ & $\begin{array}{l}\text { s. XV (2) } \\
\text { s. XV (19) }\end{array}$ \\
\hline $\begin{array}{l}\text { EGUALANZA } \\
\text { egualança }\end{array}$ & 36 casos en 15 doc. & s. XIV-XVI & $\begin{array}{l}32 \text { casos en } 17 \\
\text { doc. }\end{array}$ & $\begin{array}{l}\text { s. XIII (3) } \\
\text { s. XIV (5) } \\
\text { s. XV (17) } \\
\text { s. XVI (7) }\end{array}$ \\
\hline IGUALANZA & 3 casos en 1 doc. & s. XVII & $\begin{array}{l}3 \text { casos en } 1 \\
\text { doc. }^{22}\end{array} \mid$ & s. XVII \\
\hline ygualanza & 1 caso en 1 doc. & s. XV & 1 caso en 1 doc. & s. XV \\
\hline ygualança & 41 casos en 19 doc. & s. XIII-XV & $\begin{array}{l}43 \text { casos en } 20 \\
\text { doc. }\end{array}$ & $\begin{array}{l}\text { s. XIII (3) } \\
\text { s. XIV (3) } \\
\text { s. XV (37) }\end{array}$ \\
\hline EGUALIDAD & 1 caso en 1 doc. & s. XV & 1 caso en 1 doc. & s. XV \\
\hline IGUALIDAD & 1 caso en 1 doc. & s. XVII & 1 caso en 1 doc. & s. XVII \\
\hline
\end{tabular}

Esta situación de relación de voces, de remisión de unas a otras y de escasa documentación textual, favorece $-\mathrm{y}$ explica- su supresión del diccionario, además de su consideración de arcaísmos gráficos (incluso de aquellos en apariencia morfológicos).

Otros ejemplos de arcaísmos gráficos con vacilación vocálica en posición inicial, extraídos del corpus y eliminados en la sexta edición, son los siguientes casos de alternancia $e / a$ y $e / i$, en los que la primera forma es la eliminada: emelga/amelga $a^{23}$, emparar/amparar, empolla/ampolla, y empedir, empedimiento y empedido por impedir, impedimiento e impedido, emportunar/importunar, empremir/imprimir y emponer/imponer ${ }^{24}$.

22 Son los mismos casos y el mismo texto que aparece en el CORDE (consulta 8.2.2017).

23 Se elimina, pero no tiene marca de arcaísmo.

24 De estas voces, emelga aparece ya en Covarrubias (DECH, s. v. amelga); emparar en el Cid y en Berceo (DECH, s. v. parar); emponer en Berceo y Alexandre (DECH, s. v. poner); las variantes empedir, empremir, empolla y emportunar no se recogen en el $D E C H$. 
4.1.1.2. En posición interior, formas como abondado, abondancia, abondante, abondantemente y abondar, por un lado, y, por otro, debujado, debujadura, debujar y debujo muestran un comportamiento similar en la supresión, por ser arcaísmos gráficos, pero diferente en las razones que llevan a esa supresión, a su consideración de arcaísmos gráficos:

\begin{tabular}{|c|c|c|}
\hline Posición interior & DRAE 1817 & DRAE 1822 \\
\hline ABONDADO & p.p. de ABONDAR & $\varnothing$ \\
\hline ABONDANCIA & ant. Lo mismo que ABUNDANCIA & \\
\hline ABONDANTE & p. a. ant. de ABUNDAR. Lo que abunda & \\
\hline ABONDANTEMENTE & $\begin{array}{l}\text { adv. m. ant. Lo mismo que } \\
\text { ABUNDANTEMENTE }\end{array}$ & \\
\hline ABONDAR [2] & ant. Lo mismo que ABUNDAR & \\
\hline $\mathrm{ABONDO}^{25}$ & ant. Lo mismo que ABUNDANCIA & \\
\hline DEBUJADO & p.p. ant. de DEBUJAR & $\varnothing$ \\
\hline DEBUJADURA & ant. DIBUJO o DISEÑO & \\
\hline DEBUJAR & ant. Lo mismo que DIBUJAR & \\
\hline DEBUJO & ant. Lo mismo que DIBUJO & \\
\hline
\end{tabular}

Documentadas en Autoridades 1726-1739, abondo es la base que determina la suerte de las derivadas. Ya en este primer diccionario se indica que es "término antiguo, que significa lo mismo que Abundancia"26, y su derivado abondar "es voz antigua y de poco uso, porque comúnmente se dice abundar"27. Esta valoración la comparten los participios abondado y abondante, y el adverbio abondantemente, pues la primera se marca como arcaísmo en la segunda edición de este diccionario, de 1770, y las otras dos cuando se introducen en el suplemento de la primera edición, de 1780. Muestra esta progresiva incorporación de voces de este tipo el interés de la Academia por consignar arcaísmos - como los de la familia léxica de egual-, así fueran variantes más tarde eliminadas (Azorín 2018: 437-438; Muñoz 2018: 214). Y muestra también esta progresiva marcación de voces cómo el carácter anticuado de una palabra hace que lo adopten otras con las que se tiene una relación morfológica.

25 Ejemplo de vocal tónica.

26 Remite a abundancia, voz usual, no a abundo, registrada también en el diccionario, marcada como arcaísmo y mantenida hasta la $22^{\mathrm{a}}$ edición, de 2001.

27 Abondar es forma corriente desde Berceo hasta el siglo XVI (DECH, s. v. onda). 
En debujar, y en las relacionadas con ella, se da la misma situación vista hasta ahora, en lo relativo a la inserción, conservación y eliminación. Una diferencia con respecto al grupo anterior, al grupo de abondar, está en la edición en que fueron incorporadas estas voces: debuxar se incorpora en la tercera edición, de 1791, y como ella debuxado, debuxadura y debuxo. Lo hacen en este momento -como las vistas del grupo de egual-porque es entonces cuando la revisión del Diccionario de autoridades, proyectada por la Academia tras la reducción de la obra en 1780, llega a la letra D. Y otra diferencia -de mayor relevancia- es que, mientras el ejemplo anterior, el de abondar, es explicable por la vacilación del vocalismo átono (lat. abundāre) con triunfo de la forma etimológica, fruto del influjo de latinismos de esta familia léxica en español (Clavería 1991: 179-180 y 193, Clavería 1995: 370) ${ }^{28}$, en este otro ejemplo su origen foráneo (fr. ant. deboissier) y la documentación de las formas debuxo, debuxar, etc. en el Vocabulario de Nebrija, muestran que el cambio vocálico, causado por un cambio de prefijo (DECH, s. v. dibujar, nota 1) y por analogía con otras formas con alternancia $e / i$, deriva en el triunfo de una forma no etimológica. Así, mientras en el primer caso el diccionario muestra que se impone la etimología (abondar) abundar), en este otro puede decirse que lo hace el uso (debujar/dibujar) ${ }^{29}$, como razón para la determinación del arcaísmo gráfico y su supresión del diccionario $^{30}$.

Como en los casos anteriores, estos son ejemplos de inserción de arcaísmos en el diccionario: en el proceso de revisión del diccionario, del diccionario "grande" (Seco 1993 [2003]: 337), que entonces iba por la D, se producen aumentos en la macroestructura, voces en uso y arcaísmos, variantes gráficas arcaicas, etc. Cuando la Academia repara en que una cosa es el diccionario "grande" y otra el reducido a un tomo -el compendio-, y que el "compendio" ya no es el de Autoridades -el diccionario "grande"-, entonces empezará a suprimir lo incorporado por ser propio de otro tipo de

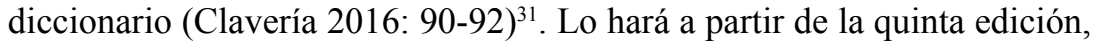
de 1817 (Clavería y Freixas 2015: 1310; Clavería y Freixas 2018), y en la sexta, con la supresión de arcaísmos gráficos como estos.

28 Vid. el prólogo de la sexta edición en que pusición por posición es calificado como corrupción.

29 La primera documentación de la voz es debuxar en Berceo (DECH, s. v. dibujar).

30 El DECH, s. v. dibujar recoge la forma dibujar en 1570. En Autoridades 1726-1739 aparece dibuxar, y en esa entrada se indica que "en lo antiguo se decía Debuxar".

31 Después de ese reconocimiento surgirá la idea de otro tipo de diccionario, uno "manual", que, si bien se apunta ya en el siglo XIX, no será realidad hasta el primer cuarto del siglo XX (Fries 1989: 66). 
Al lado de estos ejemplos, otros arcaísmos gráficos extraídos del corpus, que presentan cambios vocálicos de la vocal átona en posición interior, y que se eliminan, son las primeras formas de las siguientes parejas: abejeruco/abejaruco, abstenencia/abstinencia, abuchornarse/abochornarse, abuhetado/abohetado, barjoleta/barjuleta, caristía/carestía, carpentero/ carpintero, demetir/dimitir, fáleris/fálaris, joventud/juventud, malivolencia y malivolo por malevolencia y malévolo, mastriscolía/maestrescolía, maestriscuela/maestrescuela, sabidoría/sabiduría ${ }^{32}$.

4.1.1.3. En posición final, por último, el uso del arcaísmo gráfico cas por casa es explicado en Autoridades 1726-1739 de esta manera: 'Lo mismo que casa: y aun assi se dice en muchos lugares, hablando con poco reparo y abreviando la pronunciacion. ${ }^{33}$ Este ejemplo, como los anteriores, muestra un cambio en la pronunciación, en la articulación, por "transgresión" o "corrupción", a diferencia de lo que sucede en otros casos como debile/débil, eficaceleficaz, facile/fácil, imbécile/imbécil, útile/útil, verisímile/verosímil (lat. debülis, lat. efficax, lat. facŭlis, lat. imbecillis, lat. utĭlis y lat. verisimilis), que reflejan no tanto una fase en la evolución del latín al castellano, un estadio temprano de esa evolución, cuanto, dada la tendencia cultista de los siglos XV y XVI, una imitación de la lengua latina, una adaptación como préstamos (Pascual 1974: 171-172, Dworkin 2004: 652), ahora eliminada ${ }^{34}$ :

\begin{tabular}{|l|l|l|}
\hline \multicolumn{1}{|c|}{ Posición final } & \multicolumn{1}{c|}{ DRAE 1817} & DRAE 1822 \\
\hline CAS & ant. Lo mismo que CASA & $\varnothing$ \\
\cline { 1 - 2 } SALZ & ant. Lo mismo que SAUCE & \\
\hline
\end{tabular}

32 Barjoleta aparece ya en el s. XIII (DECH, s. v. barjuleta); caristía, forma común y muy frecuente del bajo latín; el diccionario histórico de la Academia recoge dos testimonios del siglo XVI (DECH, s. v. carestía); carpentero, forma antigua (DECH, s. v. carpintero); joventud, forma culta, en Juan Ruiz ( $D E C H$, s. v. joven). Las otras formas citadas no aparecen en el $\mathrm{DECH}$.

33 Esta consideración de cas/casa hace que vuelva a incorporarse al diccionario en la duodécima edición, de 1884, sin marca de arcaísmo y con la observación de que "hoy solo tiene uso entre gente del pueblo". No aparece esta forma en el DECH, s. v. casa; tampoco la recoge Menéndez Pidal (1987).

34 Alcoba (2007: 31) los considera neolatinismos creados por afectación.

35 Para este resultado, cf. Menéndez Pidal (1987: 169), que explica salce, saz, o calce, caz. 


\begin{tabular}{|c|c|c|}
\hline Posición final & $D R A E 1817$ & $D R A E 1822$ \\
\hline DEBILE & ant. Lo mismo que DÉBIL & \multirow[t]{7}{*}{$\varnothing$} \\
\hline EFICACE & ant. Lo mismo que EFICAZ & \\
\hline EFICACEMENTE & ant. Lo mismo que EFICAZMENTE & \\
\hline FACILE & ant. Lo mismo que FÁCIL & \\
\hline IMBÉCILE & ant. Lo mismo que IMBÉCIL & \\
\hline U'TILE & ant. Lo mismo que ÚTIL & \\
\hline VERISÍMILE & ant. Lo mismo que VERISÍMIL & \\
\hline
\end{tabular}

Todas estas voces se documentan por primera vez en la edición de 1803, excepto débile, fácile y eficace, que lo hacen en la de $1791^{36}$ : débile, imbécile y útile solo están en el diccionario académico; el resto las incorporan también otros diccionarios, como el de Nebrija (eficace), o en el siglo XIX los de Salvá y Domínguez, lo que testimonia el interés por su conservación más allá del diccionario académico.

\subsubsection{Mantenimiento}

Lo expuesto hasta aquí muestra cómo la Academia, guiada por el deseo de aumentar la nomenclatura de su diccionario y de hacerlo con arcaísmos por las razones expuestas en el prólogo de la segunda edición del Diccionario de autoridades, recurre a un grupo concreto de ellos, los arcaísmos gráficos, que testimonian fases de la evolución de una palabra a lo largo de la historia y obedecen también a transgresiones e incorrecciones en la pronunciación.

Si esa decisión se concretó en 1770 , en un diccionario y en un momento en que se tenía una concepción determinada de lo que habría de ser esta obra, como se ha señalado más arriba (DRAE 1780: Prólogo; Fernández Sevilla 1974: 47-48; Fries 1989: 79-80), y en las posteriores, más de medio siglo después, en 1822, la situación cambió, fruto de la renovación que se había producido ya en 1817 y que había hecho del diccionario una obra nueva (Clavería 2016: 88; Clavería y Freixas 2018). No obstante, no todos los ejemplos que estaban en la situación que se acaba de describir fueron suprimidos, pues otros, que presentan fenómenos similares a los eliminados, se mantuvieron:

36 Se incorporaron en las ediciones en que fueron revisadas esas letras, excepto veyece, que aparecía ya en Autoridades 1726-1739. 


\begin{tabular}{|c|c|c|}
\hline Posición inicial & $D R A E 1817$ & $D R A E 1822$ \\
\hline EGLESIA $^{37}$ & ant. Lo mismo que IGLESIA & ant. IGLESIA \\
\hline EMPRIMIR $^{38}$ & ant. Lo mismo que IMPRIMIR & ant. IMPRIMIR \\
\hline Posición interior & $D R A E 1817$ & DRAE 1822 \\
\hline ABESTIONAR & ant. Lo mismo que ABASTIONAR & ant. ABASTIONAR \\
\hline ABOLONGO & ant. Lo mismo que ABOLENGO & ant. ABOLENGO \\
\hline CANCHALAGUA & ant. Lo mismo que CANCHELAGUA & $\begin{array}{l}\text { Planta anua de America, } \\
\text { especie de genciana muy } \\
\text { semejante a la centaura } \\
\text { menor, y que se usa en la } \\
\text { medicina }\end{array}$ \\
\hline & & ant. DICIEMBRE \\
\hline DECIEMBRE & ant. Lo mismo que DICIEMBRE & ant. JUGLAR \\
\hline JOGLAR & ant. Lo mismo que JUGLAR & ant. JUAN \\
\hline JOAN & ant. Lo mismo que JUAN & ant. NAFA \\
\hline NEFA & ant. Lo mismo que NAFA & ant. RENCOR \\
\hline RANCOR & ant. Lo mismo que RENCOR & ant. SELVÁTICO \\
\hline SALVÁTICO & ant. Lo mismo que SELVÁTICO & ant. TALANTE \\
\hline TALENTE $^{39}$ & ant. Lo mismo que TALANTE & ant. VENTOSIDAD \\
\hline VENTOSEDAD ${ }^{40}$ & ant. Lo mismo que VENTOSIDAD & \\
\hline $\begin{array}{c}\text { Posición final } \\
\text { Alternancia vocálica }\end{array}$ & DRAE 1817 & DRAE 1822 \\
\hline ABETE & ant. Lo mismo que ABETO & ant. ABETO \\
\hline BARBARIA & ant. Lo mismo que BARBARIE & ant. BARBARIE \\
\hline HARTAZGA & ant. Lo mismo que HARTAZGO & ant. HARTAZGO \\
\hline
\end{tabular}

37 Primera forma documentada de la voz, presente en Berceo. Desde la segunda mitad del siglo XIV se impone iglesia, única forma registrada por Nebrija (DECH, s. v. iglesia).

38 Vid. empremir, que se eliminó, como se ha señalado más arriba.

39 Es un caso de mantenimiento de variante gráfica vocálica acentuada.

40 Esta voz presenta una variación gráfica ligada a la morfología. 


\begin{tabular}{|l|l|l|}
\hline \multicolumn{1}{|c|}{$\begin{array}{c}\text { Posición final } \\
\text { Apócope }\end{array}$} & \multicolumn{1}{c|}{ DRAE 1817} & \multicolumn{1}{c|}{ DRAE 1822} \\
\hline CAL & ant. Lo mismo que CALLE & ant. CALLE \\
\hline CASTEL & ant. Lo mismo que CASTILLO & ant. CASTILLO \\
\hline DELIBERADAMENT & $\begin{array}{l}\text { ant. Lo mismo que } \\
\text { DELIBERADAMENTE }\end{array}$ & $\begin{array}{l}\text { ant. } \\
\text { DELIBERADAMENTE }\end{array}$ \\
\hline FALACE & ant. Lo mismo que FALAZ & ant. FALAZ \\
\hline VELOCE & ant. Lo mismo que VELOZ & ant. VELOZ \\
\hline
\end{tabular}

Se ha señalado más arriba, al comentar el prólogo de la sexta edición, que la idea era suprimir solo aquellas voces cuyo significado se comprendiera con facilidad y cuya composición se mantuviera en las que las habían sustituido. No parece que las voces que se acaban de citar no estuvieran en esta situación, a pesar de lo cual se mantuvieron. No son muchas, si se comparan con las eliminadas; con todo, las letras a las que pertenecen y la variedad de fenómenos afectados muestran que se mantuvieron por un deseo consciente de mantenerlas, no porque se descuidara su eliminación en la revisión del diccionario.

Abestionar por abastionar, por ejemplo, se documenta por primera vez en la cuarta edición, de 1803, marcada como voz de raro uso; en la quinta pasó a ser anticuada, consideración que ha tenido hasta la vigésima primera edición, de 1992, en que se marcó como desusada ${ }^{41}$. Pero lo relevante de esta voz no es el cambio de marcas diacrónicas, sino la adopción en la $12^{\mathrm{a}}$ edición, de 1884 , de la marca Mil[icia] y a partir de la $13^{\text {a }}$, de 1899 , de Fort[ificación]. De este uso restringido de la voz dan cuenta los dos únicos testimonios que ofrece el $D H 1933$, pertenecientes a este registro, distintos de los dos que recogen también el CORDE y el $C D H^{42}$.

Si esta voz se caracteriza por tener restricción diastrática, y eso parece ser lo que determina su mantenimiento, canchalagua y sus variantes canchelagua, canchilagua presentan restricción diatópica. Terreros registra en su diccionario las tres variantes de este indoamericanismo ${ }^{43}$ como lemas de la misma entrada (Terreros 1786-1793: 333), y la Academia marca la

41 En la última edición del diccionario ya no aparece.

42 Se trata de Escalante, Diálogo Arte Militar, y Mendoza, Guerra de Flandes (DH 1933, s. $v$.). En los corpus los textos son de Frey Juan Villela, de 1552, y Fray Prudencio de Sandoval, de 1604.

43 Vid. DECH, s. v. canchalagua. 
primera como arcaica. Lo hace solo en la quinta edición, de 1817, al tener que cambiar la marca de poco usado de la edición anterior. Este hecho, que tiene que ver con lo lexicográfico más que con lo léxico, por una cuestión de reajuste de marcas diacrónicas efectuada entonces (Jiménez Ríos 2018: 402-403), se corrige en la sexta edición, pues no era en puridad un arcaísmo, de modo que canchalagua es la forma que se define y canchelagua remite sin marca a 'Planta CANCHALAGUA'44.

Otras formas mantenidas en ediciones posteriores a la sexta están en distinta situación: unas, como joglar, parece que se conservan por su presencia en textos fundamentales de época medieval ( $D E C H$, s. v. juego); otras, como rancor, por la conveniencia de mostrar la forma etimológica, luego sustituida por rencor, que resulta de la analogía con el prefijo re-. (DECH, s. v. rancio).

En los casos de vacilación gráfica en posición final, además de la apócope de formas como falacelfalaz, veloce/veloz, o mejor dicho, de formas latinas recuperadas, hay otras voces con vacilación vocálica, como abetelabeto o barbaria/barbarie. Se trata de variantes, formas de un estado anterior de la lengua, la primera reinterpretada más tarde como voz dialectal ${ }^{45}$; y la segunda, al igual que selvático, muestra de la importancia de la etimología ${ }^{46}$. Más interesante, por lo relevante, es el mantenimiento de cal/calle $e^{47}$ y castel/ castillo $^{48}$, que puede decirse que se conservaron por la idea de mantener -ahora sí- aquellos arcaísmos que no contaran con equivalentes modernos en que se reconocieran.

Con todo, la conclusión que se extrae del examen de arcaísmos gráficos con cambio vocálico es que la mayoría de las voces anticuadas que están en esta situación se eliminaron en el paso de la quinta a la sexta edición, lo que no impidió que se siguieran manteniendo, por contar con una información adicional más allá de la meramente diacrónica o por prestigiar unas formas frente a otras, las ligadas a la etimología, arcaísmos con características similares a los eliminados.

44 No debería tener marca diacrónica, que resulta de una mala interpretación de la restricción de poco uso, por lo dialectal, que tenía con anterioridad a 1817. Vid. también DECH, s. v. canchalagua.

45 En la $21^{\text {a }}$ edición, de 1992, “desus. Abeto. Ú. hoy en el Alto Aragón.” En su formación abeto es adaptación del arag. abete (DECH, s. v. abeto).

46 Barbarie, del lat. barbaries, no aparece en $D E C H$, s. v. bárbaro.

47 Cal y Castil, vid. Menéndez Pidal (1987: 169).

48 Castil aparece solo en Autoridades 1726-1739 (y en diccionarios no académicos del siglo XIX). 


\subsection{ARCAÍSMOS GRÁFICOS CON CAMBIOS CONSONÁNTICOS}

Los cambios consonánticos en los arcaísmos gráficos manejados aquí son más abundantes que los vocálicos y la tipología también lo es. Esto es así porque es en la ortografía de los sonidos consonánticos y de los grupos formados por ellos donde hay más variedad y confusión, como ya había manifestado la Academia en su Discurso proemial de la orthographia (Discurso: LXVIII, LXXIX). Destacan los cambios que se producen en grupos consonánticos formados por la concurrencia de diversas consonantes (Discurso: LXXIX-LXXXII; Terrón 2018: 87-88) y los de la posición inicial, en la que sobresale la suerte de la F latina.

\subsubsection{Supresión}

4.2.1.1. En arcaísmos gráficos con cambios consonánticos en posición interior (posición implosiva), se suprimen del diccionario formas con distintos grupos consonánticos:

a) Grupos $-B T-,-B D-,-B S$ -

Abto, abtor, abtoridad (abtoridat), abtorizado y abtorizar revelan cambios gráficos más que cambios en la pronunciación ${ }^{49}$, al igual que abtual ${ }^{50}$, cabtela y cabteloso $^{51}$, abdiencia ${ }^{52}$, o cabsa, cabsado, cabsador y cabsar ${ }^{53}$ (lat. auctorìtas, lat. cautela, lat. causa, lat. actuālis, lat. causāre) (SánchezPrieto 2002: 1305). A diferencia de ellas, formas como debda, debdado, debdo [1], debdo [2], debdo [3], debdor y debdoso (lat. debita) manifiestan una fase de su evolución en la lengua (Menéndez Pidal 1987: 162) ${ }^{54}$ :

49 En DECH s. v. autor no se recogen estas grafías, solo una forma abtoryzar, que se explica como ultracorrección en el Cancionero de Baena.

50 El DECH s. v. acta la recoge en 1460.

51 No están estas formas en $D E C H, s$. v. cauto.

52 No está en $D E C H$, s. v. oír.

53 No están estas formas en $D E C H, s . v$. causa.

54 Debda y debdo son anticuadas (DECH, s. v. deber). Todas estas formas han de interpretarse como el mantenimiento en la lengua $-\mathrm{y}$ luego en el diccionario- de formas antiguas, no como neolatinismos (Alcoba 2007: 31). 


\begin{tabular}{|c|c|c|}
\hline Grupo -BT- & $D R A E 1817$ & $D R A E 1822$ \\
\hline ABTO & ant. Lo mismo que ACTO ó AUTO & \multirow[t]{10}{*}{$\varnothing$} \\
\hline ABTOR & ant. Lo mismo que AUTOR & \\
\hline ABTORIDAD & ant. Lo mismo que AUTORIDAD & \\
\hline ABTORIDAT & ant. Lo mismo que AUTORIDAD & \\
\hline ABTORIZADO & p.p. ant. de ABTORIZAR & \\
\hline ABTORIZAR & ant. Lo mismo que AUTORIZAR & \\
\hline ABTUAL & ant. Lo mismo que ACTUAL & \\
\hline ABTUALMENTE & ant. Lo mismo que ACTUALMENTE & \\
\hline CABTELA & ant. Lo mismo que CAUTELA & \\
\hline CABTELOSO & ant. Lo mismo que CAUTELOSO & \\
\hline Grupo -BD- & $D R A E 1817$ & $D R A E 1822$ \\
\hline ABDIENCIA & ant. Lo mismo que AUDIENCIA & \multirow[t]{8}{*}{$\varnothing$} \\
\hline DEBDA & ant. Lo mismo que DEUDA & \\
\hline DEBDADO & ant. Lo mismo que ADEUDADO & \\
\hline DEBDO [1] & $\begin{array}{l}\text { ant. Lo mismo que DEUDO por } \\
\text { parentesco }\end{array}$ & \\
\hline DEBDO [2] & $\begin{array}{l}\text { ant. Lo mismo que RELACIÓN, } \\
\text { DEPENDENCIA O ALIANZA de un } \\
\text { hombre con otro, aunque no sea de } \\
\text { parentesco }\end{array}$ & \\
\hline DEBDO [3] & ant. Débito o deuda & \\
\hline DEBDOR & ant. Lo mismo que DEUDOR & \\
\hline DEBDOSO & $\begin{array}{l}\text { ant. Lo mismo que ADEUDADO o } \\
\text { EMPARENTADO, o lo perteneciente } \\
\text { a deudo o parentesco }\end{array}$ & \\
\hline Grupo -BS- & $D R A E 1817$ & $D R A E 1822$ \\
\hline CABSA & ant. Lo mismo que CAUSA & $\varnothing$ \\
\hline CABSADO & p.p. ant. de CAUSAR & \\
\hline CABSADOR & ant. Lo mismo que CAUSADOR & \\
\hline CABSAR & ant. Lo mismo que CAUSAR & \\
\hline
\end{tabular}

El primer grupo de voces había sido incorporado en el suplemento de la primera edición del diccionario, de 1780 (a excepción de abtoridad, registrada ya en 1770). Su incorporación, como en el caso de los arcaísmos con variación vocálica, responde al deseo de recoger arcaísmos en el diccionario; además, estas variantes gráficas contaban con el aval de 
autoridad de los textos que las documentaban (de los que da muestra el DH $1933^{55}$ ). Con posterioridad fueron eliminadas por tratarse de arcaísmos gráficos, pero, sobre todo, porque no respondían a la etimología, sino que eran fruto de una tradición gráfica ya pasada.

A diferencia de este grupo de ejemplos, las voces citadas a continuación - debda y derivados-, que reflejan una fase de la evolución gráfico-fonética en la lengua $\left(D E C H, s . v\right.$. deber $\left.{ }^{56}\right)$, se incorporan al diccionario en la tercera edición, de 1791, en que la revisión de Autoridades llegó a la letra D. Con todo, la diferencia con las formas anteriores está en la recuperación posterior de alguna de ellas, precisamente porque eran diferentes a aquellas (Terrón 2018: 87-89). Así, debda y debdo, eliminadas en la sexta edición, retornan al diccionario en la duodécima, de 1884, y se mantienen hasta hoy ${ }^{57}$; y lo hacen, podría decirse, por el tendencia de la corporación académica a conservar la lengua del pasado (Martínez de Sousa 1991: 58; García de la Concha 2014: 205), con el mismo criterio - y con la misma añoranza- que manifestaba el autor del Diálogo de la lengua, a propósito de formas como cobdo y dubda: "los vocablos están más llenos y mejores con la $b$ que sin ella, y porque toda mi vida los he scrito y pronunciado con $b$ " (Barbolani 1995: 168) $)^{58}$ ).

b) Grupo $S C$ -

El grupo -SC- destaca entre los arcaísmos gráficos con cambios consonánticos, pues todas las formas extraídas del corpus se suprimen en el $D R A E 1822$ porque "su uso antiguo las hacia ásperas y desabridas" (DRAE 1822: Prólogo):

55 Vid. $D H 1933, s$. v. Son palabras con grafías propias de un determinado registro, el administrativo, tendente a la introducción de palabras de origen latino en los siglos XIV y XVI (Sánchez-Prieto 2002: 1287).

56 Forma medieval; Palencia registra deuda (DECH, s. v. deber).

57 Su documentación textual y su presencia en corpus es muy abundante: debda presenta en el CORDE 1313 casos en 276 documentos y debdo 1709 casos en 270 documentos; el $C D H$ registra 1211 casos en 246 documentos de debda y 1697 casos en 258 documentos de debdo (consulta 19.2.2017).

$58 C f$. lo dicho más arriba y en $D E C H$, s. v. deber. Y cf. con lo expuesto por la Academia en el Discurso (LXIX) al señalar el abandono de formas como dubda "por haverse considerado como repugnantes à la blandura de estilo la duplicación y concurrencia de algunas consonantes". 


\begin{tabular}{|c|c|c|}
\hline Grupo $-S C->-C$ - & $D R A E 1817$ & $\begin{array}{c}D R A E \\
1822\end{array}$ \\
\hline ABORRESCEDERO & ant. Lo mismo que ABORRECIBLE & $\varnothing$ \\
\hline ABORRESCEDOR & ant. Lo mismo que ABORRECEDOR & \\
\hline ABORRESCENCIA & ant. Lo mismo que ABORRECIMIENTO & \\
\hline ABORRESCER & ant. Lo mismo que ABORRECER & \\
\hline ABORRESCIBLE & ant. Lo mismo que ABORRECIBLE & \\
\hline ABORRESCIDO & p.p. ant. de ABORRESCER & \\
\hline ABORRESCIMIENTO & ant. Lo mismo que ABORRECIMIENTO & \\
\hline CARESCER & ant. Lo mismo que CARECER & \\
\hline CARESCIENTE & p.a. ant. de CARESCER. Lo que carece & \\
\hline CARESCIMIENTO & ant. Lo mismo que CARENCIA & \\
\hline CARNESCERÍA & $\begin{array}{l}\text { ant. Lo mismo que CARNICERÍA por } \\
\text { la casa donde se vende la carne y por la } \\
\text { mortandad }\end{array}$ & \\
\hline EMBOBESCIMIENTO & ant. Lo mismo que EMBOBECIMIENTO & \\
\hline EMPESCIBLE & ant. Lo mismo que EMPECIBLE & \\
\hline EMPESCIMIENTO & ant. Lo mismo que EMPECIMIENTO & \\
\hline FALLESCER & ant. Lo mismo que FALLECER & \\
\hline FALLESCIENTE & p. a. ant. de FALLECER. El que fallece & \\
\hline FALLESCIMIENTO & ant. Lo mismo que FALLECIMIENTO & \\
\hline FAVORESCEDOR & ant. Lo mismo que FAVORECEDOR & \\
\hline FAVORESCER & ant. Lo mismo que FAVORECER & \\
\hline FAVORESCIDO & p.p. ant. de FAVORESCER & \\
\hline IMPELESCER & ant. Lo mismo que IMPELER & \\
\hline NASCER & ant. Lo mismo que NACER & \\
\hline NASCIDA & ant. Lo mismo que NACIDA & \\
\hline NASCIDO & p. de NACER & \\
\hline NASCIDO [2] & $\begin{array}{l}\text { ant. Lo mismo que NACIDO por grano } \\
\text { o tumor }\end{array}$ & \\
\hline NASCIENTE & p. a. ant. de NASCER. El que nace & \\
\hline NASCIMIENTO & ant. Lo mismo que NACIMIENTO & \\
\hline OFRESCER & ant. Lo mismo que OFRECER & \\
\hline
\end{tabular}


El deseo de mantener la grafía etimológica explica la presencia de aborrescencia ( $c f$. lat. abhorrescěre ${ }^{59}$ ), registrada ya en Autoridades 17261739 (no existe en el diccionario académico una forma aborrecencia). Aborrescer, aborrescido, aborrescible, aborrescimiento y aborrescedero se incorporan en el suplemento de la primera edición y en la tercera lo hace aborrescedor. Aborrescencia, 'Lo mismo que ABORRECIMIENTO' y primera voz del grupo en documentarse es eliminada como las demás, pero se reincorpora en la undécima edición y se mantiene hasta hoy. Se mantiene por la misma razón que debda y otras voces citadas más arriba: se había suprimido porque era un arcaísmo gráfico, pero el deseo de mantener la lengua del pasado por medio de sus voces, voces que reflejaban su etimología, hizo que volviera a incorporarse al diccionario ${ }^{60}$.

Como esta voz, caresciente, forma culta, recogida ya en Autoridades 1726-1739, gozaba en ese diccionario de la autoridad del Tostado (Eusebio), y su presencia entonces determinó la inserción posterior de la base carescer (lat. carescěre) y del derivado carescimiento, luego eliminados ${ }^{61}$. Nascer, nascida, nascido, nasciente y nascimiento fueron eliminadas ${ }^{62}$; nascencia, en cambio, se conservó, pues la remisión a nacimiento no permitía reconocer en esta forma aquella a la que sustituía. Nesciencia y nesciente se mantuvieron por esta misma razón, y porque no remitían a otra voz (y, además, porque eran voces raras, como las califica el $D E C H$, s. v. ciencia). Claro que en este vaivén de supresiones y mantenimientos, nescio por necio se conservó, no habiendo ningún motivo para ello -o quizá sí, su relación con nesciencia y nesciente-, además de su documentación medieval en Berceo, Juan Ruiz, etc. ${ }^{63}$.

Precisamente en el Discurso proemial de la orthographia, la Academia ya manifestó el distinto resultado ortográfico de la "concurrencia de diversas consonantes", sobre "cuyo uso ha habido, y hai variedad en lo escrito, por la diferencia que se experimenta en el modo de proferir las palabras" (Discurso: LXX). Ligada a las voces citadas en este apartado, es clarificadora

\footnotetext{
59 No se recogen estas formas en el DECH, s. v. aburrir.

60 Se incorporó primero y se reincorporó después por esa tendencia "alatinada" con que califica Lázaro (1972 [1980]: 1089) la conservación a mediados del siglo XVIII de determinadas formas. No se documenta en el diccionario académico -sí en el de Salvá y Domínguez- una forma aborrecencia a la que remitir.

${ }_{61}$ Se incorporaron en la edición de 1780 . No se documentan estas formas en el $D E C H$, s. v. carecer.

62 No se documentan estas formas en el $D E C H$, s. v. nacer.

63 Vid. DECH, s. v. ciencia. Nescio también se recoge en la $23^{\mathrm{a}}$ edición del diccionario académico, de 2014.
} 
la explicación dada a propósito de la voz conciencia, pues, si lo normal es la realización del grupo en voces como transcendental, inscripción, conscripto, etc., en aquella voz se justifica la diferencia con la etimología por el predominio de la pronunciación: "Y aunque la voz Conciéncia várias veces en lo antíguo se halle escrita con la $s$, y no falte quien la repúte por precisa: respecto de que yá no se especifica quando se pronúncia, no hai fundamento para haver de estar à su origen, por ser ya uniforme el estilo contrario" (Discurso: LXX).

No obstante, la peculiaridad del grupo -sc-hace "dificultosisimo dar regla general", pues una es la situación cuando le siguen las vocales $e$, $i$, como ascender, adolescencia, y otra cuando lo hacen $a, o, u$, en que no se puede dudar de su pronunciación, como en escala, escota o escuela:

Nace la duda en las priméras de la variedád con que se pronúncian: y aunque los Autóres estén entre sí encontrados, porque unos retienen la $s$ en todos los vocablos, y otros la desechan como inútil: lo que se debe hacer es retenerla en algunas voces, que sin ella no se pueden legitimamente pronunciar, como en estas Ascender, Ascendencia, Ascendente, Condescender, Descender, Desceñir, Aquiescencia, Disceptación, Discernir, Disciplina, Discipulo, Adolescencia, Presciencia, Miscelánea, y en otras no, como Apacentar, Conocer, Crecer, Pacer, Adolecer, Florecer, y otras semejantes, que aunque en sus orígenes Latinos tengan $s$, en la realidád el dia de oy se pronúncian sin ella (Discurso: LXXXI).

c) Palatales y grupos de palatales

La inserción, primero, y supresión, después, de voces con distintas grafías palatales, inexistentes hoy en la lengua, responde también al interés por registrar formas arcaicas:

\begin{tabular}{|c|c|c|}
\hline $\begin{array}{c}\text { Palatales y grupos } \\
\text { de palatales }\end{array}$ & DRAE 1817 & $\begin{array}{c}\text { DRAE } \\
1822 \\
\end{array}$ \\
\hline CABANNA & ant. Lo mismo que CABAÑA & \multirow[t]{7}{*}{$\varnothing$} \\
\hline CAMELO & ant. Lo mismo que CAMELLO & \\
\hline CABAILLERO & ant. Lo mismo que CABALLERO & \\
\hline CALLEYA & ant. Lo mismo que CALLEJA & \\
\hline DAPNADO & p.p. ant. de DAPNAR & \\
\hline DAPNAR & ant. Lo mismo que CONDENAR & \\
\hline DAPNO & ant. Lo mismo que DAÑO & \\
\hline
\end{tabular}




\begin{tabular}{|l|l|l|}
\hline EMPENNADO & p.p. ant. de EMPEÑAR & \\
EMPENNAMIENTO & ant. Lo mismo que EMPEÑO & \\
EMPENNAR & ant. Lo mismo que EMPEÑAR & \\
\hline VEYECE & ant. Lo mismo que VEJEZ & \\
\hline
\end{tabular}

Cabanna (lat. tardío capanna ${ }^{64}$ ) es forma documentada en el siglo XIII en textos jurídicos ${ }^{65}$; camelo (lat. camēllus) está presente con esta grafía palatal en el Poema del Cid (DECH s. v. camello $)^{66}$; cabaillero se encuentra en dos fueros fechados en el siglo XII (Fuero de Santa Clara y Fuero de Marañón) ${ }^{67}$; y calleya registra tres testimonios en el CORDE, los tres de los siglos XIII y $\mathrm{XIV}^{68}$. Todas estas voces se incorporaron al diccionario en la primera edición, de 1780, o lo que es lo mismo, en la revisión de la letra $\mathrm{C}$ de Autoridades 1770 , tan dado a aumentar los arcaísmos del diccionario para "la inteligencia de nuestras leyes, fueros y ordenanzas, crónicas e instrumentos antiguos" (Autoridades 1770: Prólogo, Sánchez- Prieto 1998: 109-158).

A medida que se avanza en la revisión del diccionario y se publican las ediciones se incorporan otros arcaísmos gráficos con grafías que reflejan sonidos palatales: empennar y dapno lo hacen en $1791 \mathrm{y}$, recogida la base de derivación, en la edición siguiente, 1803, se incorporan empennado y empennamiento, dapnar y dapnado. Precisamente estas voces, dapno, dapnar y dapnado, con amplia documentación textual, han de ser interpretadas como ultracorrecciones, por el deseo de reforzar la pronunciación palatal (lat. damnāre ${ }^{69}$ ) con repercusión posterior en la escritura en un registro culto, pues, de los 453 testimonios registrados en el CORDE de dapno, 378 lo hacen en textos jurídicos, todos fechados entre 1348 y $1489^{70}$.

4 No se recoge esta forma en el DECH, s. v. cabaña.

65 Consulta CORDE 10.3.2017.

66 El CORDE ofrece testimonios fechados hasta el XV (consulta 10.3.2017).

67 Consulta CORDE 10.3.2017. No está en DECH s. v. caballo.

68 Se trata de un Documento de la Catedral de León, fechado en 1279, una Carta de población de la ciudad de Santa María de Albarracín, de 1300, y una Carta de venta (Colección diplomática de León), de 1307. El DECH no registra esta variante (DECH s. v. calle). En el prólogo de la sexta edición formas como puya por pulla, plumaye por plumage se citan como reprobables por "viciosa pronunciación".

69 Vid. Menéndez Pidal (1987: 139).

70 La forma plural, dapnos, se registra en 267 casos en 90 documentos, 241 también en prosa jurídica (consulta CORDE 10.3.2017). No aparece la forma dapno en el DECH, s. v. daño; tampoco empennamiento o empennar en DECH s. v. prenda. 
Con todo, estos arcaísmos gráficos fueron eliminados en 1822, a pesar de que alguna forma usual no reflejaba, como otros casos vistos más arriba, huella de la anticuada - es el caso de empennamiento/empeño-. Y si camelo/ camello se eliminó, otros arcaísmos del mismo tipo como cabalo/caballo o falido/fallido se mantuvieron, no habiendo, en principio, ningún motivo para ello.

4.2.1.2. Por último, en posición final absoluta se encuentran las formas $a b a t$, abtoridat, caridat, edat, facultat, heredat, hermandat y salut, incorporadas en la primera edición del diccionario, las dos primeras en el suplemento:

\begin{tabular}{|l|l|}
\hline \multicolumn{1}{|c|}{ Posición final } & \multicolumn{1}{c|}{ DRAE 1817} \\
\hline ABAT & ant. Lo mismo que ABAD \\
ABTORIDAT & ant. Lo mismo que AUTORIDAD \\
CARIDAT & ant. Lo mismo que CARIDAD \\
EDAT & ant. Lo mismo que EDAD \\
FACULTAT & ant. Lo mismo que FACULTAD \\
HEREDAT & ant. Lo mismo que HEREDAD \\
HERMANDAT & ant. Lo mismo que HERMANDAD \\
SALUT & ant. Lo mismo que SALUD \\
\hline
\end{tabular}

Como debda y debdo, todas estas formas presentan abundante documentación textual en los corpus ${ }^{71}$, a pesar de lo cual fueron eliminadas y nunca recuperadas (no hay ninguna forma de este tipo conservada en el diccionario). Se hizo así por su condición de arcaísmos gráficos (lat. tardío abbas, -ātis; lat. auctoritas, -ätis; lat. caritas, -ātis, lat. aetas, àtis, lat. facultas, ātis, lat. eredĭtas, attis, lat. salus, utis), pero, sobre todo, porque en la forma actual se conservaba aquella a la que habían sustituido (DRAE 1822: Prólogo).

\subsubsection{Mantenimiento}

Al lado de estos arcaísmos gráficos que se eliminan, otros se mantienen. La supresión o conservación es entendible, si las voces en que se dan estos dos fenómenos participan de los mismos rasgos. Sin embargo, hay arcaísmos,

71 Abat presenta 1588 casos en 449 documentos; abtoridat 353 casos en 133 documentos; caridat 927 casos en 131 documentos; edat 1314 casos en 266 documentos; facultat 99 casos en 76 documentos; heredat 6798 casos en 924 documentos; y salut 1586 casos en 885 documentos (consulta CORDE 10.3.2017). 
como los siguientes, mantenidos, que no difieren de otros señalados más arriba:

\begin{tabular}{|c|c|c|}
\hline Posición implosiva & $D R A E 1817$ & $D R A E 1822$ \\
\hline $\begin{array}{l}\text { ABSENCIA } \\
\text { ABSENTADO } \\
\text { ABSENTE }\end{array}$ & $\begin{array}{l}\text { ant. Lo mismo que AUSENCIA } \\
\text { p.p. ant. de ABSENTARSE } \\
\text { ant. Lo mismo que AUSENTE }\end{array}$ & $\begin{array}{l}\text { ant. AUSENCIA } \\
\text { p.p. ant. de } \\
\text { ABSENTARSE } \\
\text { ant. AUSENTE }\end{array}$ \\
\hline BACHILLERADGO & ant. El grado de bachiller & ant. El grado de bachiller \\
\hline \begin{tabular}{|l} 
BAPTISMAL \\
BAPTISMO \\
BAPTIZADO \\
BAPTIZADOR \\
BAPTIZANTE \\
BAPTIZAR \\
BAPTIZO \\
\end{tabular} & $\begin{array}{l}\text { ant. Lo mismo que BAUTISMAL } \\
\text { ant. Lo mismo que BAUTISMO } \\
\text { p.p. ant. de BAPTIZAR } \\
\text { ant. El que bautiza } \\
\text { p.a. ant. de BAPTIZAR } \\
\text { ant. Lo mismo que BAUTIZAR } \\
\text { ant. Lo mismo que BAUTIZO }\end{array}$ & $\begin{array}{l}\text { ant. BAUTISMAL } \\
\text { ant. BAUTISMO } \\
\text { p.p. ant. de BAPTIZAR } \\
\text { ant. El que bautiza } \\
\text { p.a. ant. de BAPTIZAR } \\
\text { ant. BAUTIZAR } \\
\text { ant. BAUTIZO } \\
\end{array}$ \\
\hline CABCIÓN & ant. Lo mismo que CAUCIÓN & ant. CAUCIÓN \\
\hline $\begin{array}{l}\text { CABDAL } \\
\text { CABDELLADO } \\
\text { CABDELLADOR } \\
\text { CABDELLAR } \\
\text { CABDIELLO } \\
\text { CABDILLADGO } \\
\text { CABDILLO } \\
\end{array}$ & \begin{tabular}{|l|} 
ant. Lo mismo que CAUDAL \\
p.p. ant. de CABDELLAR \\
ant. Lo mismo que CAUDILLO \\
ant. Lo mismo que ACAUDILLAR \\
ant. Lo mismo que CAUDILLO \\
ant. El empleo de caudillo \\
ant. Lo mismo que CAUDILLO \\
\end{tabular} & $\begin{array}{l}\text { ant. CAUDAL } \\
\text { p.p. ant. de CABDELLAR } \\
\text { ant. CAUDILLO } \\
\text { ant. ACAUDILLAR } \\
\text { ant. CAUDILLO } \\
\text { ant. El empleo de caudillo } \\
\text { ant. CAUDILLO }\end{array}$ \\
\hline $\begin{array}{l}\text { CABZADO } \\
\text { CABZAR } \\
\end{array}$ & $\begin{array}{l}\text { p.p. ant. de CABZAR } \\
\text { ant. Lo mismo que CAZAR }\end{array}$ & $\begin{array}{l}\text { p.p. ant. de CABZAR } \\
\text { ant. CAZAR }\end{array}$ \\
\hline $\begin{array}{l}\text { CAPTIVADO } \\
\text { CAPTIVADOR } \\
\text { CAPTIVANTE } \\
\text { CAPTIVAR } \\
\text { CAPTIVERIO } \\
\text { CAPTIVIDAD }\end{array}$ & \begin{tabular}{|l|} 
p.p. ant. de CAPTIVAR \\
ant. El que cautiva \\
p.a. ant. de CAPTIVAR. \\
El que cautiva \\
ant. Lo mismo que CAUTIVAR \\
ant. Lo mismo que CAUTIVERIO \\
ant. Lo mismo que \\
CAUTIVIDAD que es como \\
se dice mas comúnmente \\
ant. Lo mismo que CAUTIVO que \\
es como se dice mas comúnmente
\end{tabular} & $\begin{array}{l}\text { p.p. ant. de CAPTIVAR } \\
\text { ant. El que cautiva } \\
\text { p.a. ant. de CAPTIVAR. } \\
\text { El que cautiva } \\
\text { ant. CAUTIVAR } \\
\text { ant. CAUTIVERIO } \\
\text { ant. CAUTIVIDAD }\end{array}$ \\
\hline
\end{tabular}




\begin{tabular}{|c|c|c|}
\hline DEMONSTRABLE & ant. Lo mismo que & ant. DEMOSTRABLE \\
\hline DEMONSTRACIÓN & $\begin{array}{l}\text { DEMOSTRABLE } \\
\text { ant. Lo mismo que } \\
\text { DEMOSTRACION }\end{array}$ & ant. DEMOSTRACION \\
\hline DEMONSTRADO & p.p. de DEMONSTRAR & p.p. de DEMONSTRAR \\
\hline DEMONSTRADOR & El que demuestra & El que demuestra \\
\hline DEMONSTRAMIENTO & ant. Lo mismo que & \\
\hline & DEMOSTRAMIENTO & DEMOSTRAMIENTO \\
\hline DEMONSTRAR & ant. Lo mismo que DEMOSTRAR & ant. DEMOSTRAR \\
\hline
\end{tabular}

El mantenimiento del grupo de voces de absencia, baptizar, captivar o demonstrar responde a la conservación de la forma etimológica (lat. absentia; lat. baptizāre; lat. captivāre; lat. demonstrāre) ${ }^{72}$. Documentadas la mayoría desde Autoridades $1726-1739^{73}$, su presencia llega hasta hoy ${ }^{74}$, y sucede así no porque se trate de formas que reflejen fases de la evolución histórica de la palabra o distintas formas de pronunciación o de solución gráfica, tampoco porque sean arcaísmos gráficos que no deberían haber sido eliminados, pues la forma que las sustituye las refleja adecuadamente, sino porque la identificación de dichas formas con su etimología es determinante para su conservación (en un momento en que el diccionario no registra la etimología de las voces). Entre ellas destacan demonstrar y sus derivados, por el grupo consonántico que contienen en su interior y al que la Academia se había referido ya en el Discurso proemial de la orthographia:

La única diferencia es sobre el verbo Demostrar, que algunos le escriben con $n$, diciendo Demonstrar; pero no teniéndola el simple Mostrar, de que se compone, aunque en su raíz Latina la tenga, parece que es consiguiente escribirle sin ella; aunque no será reparable lo contrario, por retenerla el nombre Demonstración y sus derivados (Discurso: LXXX-LXXXI).

Y porque, como muestra este texto, con su mantenimiento no solo se conserva un uso del pasado, sino que se orienta sobre la pronunciación de una voz, y de otras en que pudieran concurrir los mismos sonidos, cumpliéndose

72 Cf. Discurso (LXXIX).

73 En Autoridades 1770 se insertan absentado, bachilleradgo, baptismal, batizador; cabdellado, cabellador, cabdellar, cabdiello y captivador se insertan en la primera edición, de 1780, y en el suplemento de esa edición baptizante. Cabzado se incorpora en 1803.

74 Los participios absentado, baptizado, cabdellado, captivado, demonstrado, y las voces cabdilladgo y cabzar solo están en el diccionario hasta el DRAE 1822. 
así con el cometido normativo propio de la Ortografía, pero también del Diccionario, de entonces y de ahora ${ }^{75}$.

\subsection{OtROS ARCAÍSMOS GRÁFICOS SUPRIMIDOS Y MANTENIDOS}

\subsubsection{Formas determinadas por la etimología}

Entre las formas suprimidas y mantenidas ligadas a su etimología destacan los casos de $\mathrm{F}$ en posición inicial de palabra e inicial de sílaba interior. Los ejemplos del corpus manejado muestran que los casos mantenidos son más que los suprimidos, y en ellos se percibe la tendencia a suprimir los que tienen $\mathrm{F}$ en posición interior y a mantener los de $\mathrm{F}$ en posición inicial:

\begin{tabular}{|l|l|}
\hline Supresión DRAE 1817: F- & \multicolumn{1}{|c|}{ Mantenimiento DRAE 1822: F- } \\
\hline FACA. sin marca. Lo mis- \\
mo que HACA & FACEDERO ant. Lo mismo que HACEDERO \\
& FACEDOR ant. Lo mismo que HACEDOR \\
& FACINA ant. Lo mismo que HACINA \\
& FADAR ant. Lo mismo que HADAR \\
& FADO ant. Lo mismo que HADO \\
& FALAGAR ant. Lo mismo que HALAGAR \\
& FALAGO ant. Lo mismo que HALAGO \\
& FAMBRE ant. Lo mismo que HAMBRE \\
& FAMBRIENTO ant. Lo mismo que HAMBRIENTO \\
& FAME ant. Lo mismo que HAMBRE. Hoy tiene uso \\
& en Galicia \\
& FARINA ant. Lo mismo que HARINA \\
& FARTAR ant. Lo mismo que HARTAR \\
& FARTO ant. Lo mismo que HARTO \\
& FARTURA ant. Lo mismo que HARTURA \\
& FASTA ant. Lo mismo que HASTA \\
& FASTIAL ant. Arq. Lo mismo que HASTIAL \\
& FASTÍO ant. ant. Lo mismo que HASTÍO \\
\hline Supresión DRAE 1817: -F- & \multicolumn{1}{|c|}{ Mantenimiento DRAE 1822: -F- } \\
\hline
\end{tabular}

75 Vid. Lázaro (1972 [1980]): 106), Castillo 1992: 534). Vid. también ORAE 2010: 6.5.2.2.2. y 6.5.2.2.2.1 y DRAE 2014, s. v. demonstrar, subministrar, etc. 


\begin{tabular}{|l|l|}
\hline MALFEITOR ant. Lo & CABRAFIGAR ant. Lo mismo que CABRAHIGAR \\
mismo que MALHECHOR & CABRAFIGO ant. Lo mismo que CABRAHIGO \\
SAFUMADO p.p. de & CAFIZ ant. Lo mismo que CAHIZ \\
SAFUMAR & \\
SAFUMAR ant. Lo mismo & RAFEZ ant. Lo mismo que RAHEZ \\
que SAHUMAR & TAFULLA ant. Lo mismo que TAHULLA \\
SAFUMERIO ant. Lo & TAFUR ant. Lo mismo que TAHUR \\
mismo que SAHUMERIO & VAFO ant. Lo mismo que VAHO \\
\hline
\end{tabular}

En otras formas, que reflejan también la etimología, no es fácil explicar por qué unas se eliminan y otras se mantienen: capo por cabo (lat. caput), impropriamente, impropriado e impropiar por impropiamente, impropiado e impropiar (lat. improprius), son eliminadas del diccionario; en cambio, cader por caer (lat. caděre), delicto por delito (lat. delicto), manutener por mantener (lat. manu tenēre), e, incluso, impropriedad por impropiedad o improprio por impropio se conservan ${ }^{76}$.

\subsubsection{Formas determinadas por la pronunciación}

Hay otros ejemplos, arcaísmos gráficos, cuya forma refleja un cambio en la pronunciación; unos se conservan y otros son eliminados.

El grupo formado por cativación, cativado, cativamiento, cativazón, cativerio y catividad, eliminado del diccionario, refleja la relajación en la pronunciación (frente a las formas captivado, captivador, captivante, captiverio, captividad y captivo, fieles a la etimología y mantenidas, como se ha visto más arriba):

\begin{tabular}{|l|l|l|}
\hline \multicolumn{1}{|c|}{ Palabra } & \multicolumn{1}{|c|}{ DRAE 1817 } & DRAE 1817 \\
\hline CATIVACIÓN & ant. Lo mismo que CAUTIVERIO & $\emptyset$ \\
CATIVADO & p.p. ant. de CATIVAR & \\
CATIVAMIENTO & ant. Lo mismo que CAUTIVERIO & \\
CATIVAZÓN & ant. Lo mismo que CAUTIVERIO & \\
CATIVERIO & ant. Lo msmo que CAUTIVERIO & \\
CATIVIDAD & ant. Lo mismo que CAUTIVIDAD & \\
\hline
\end{tabular}

76 Se conservan en el diccionario hasta hoy. En manutener se especifica en DRAE 1817 que "úsase hoy en lo forense". 
A su lado otros ejemplos, suprimidos y mantenidos, de grupos consonánticos con cambios por debilitamiento de la pronunciación y pérdida de sonidos implosivos son los siguientes:

\begin{tabular}{|l|l|}
\hline \multicolumn{1}{|c|}{ Supresión DRAE 1817} & \multicolumn{1}{|c|}{ Mantenimiento DRAE 1822} \\
\hline ECETUADO p.p. de ECETUAR & ECEPTO ant. EXCEPTO \\
ECETUAR ant. Lomismo queEXCEPTUAR & ECEPTUADO p.p. de ECEPTUAR \\
ECLISE ant. Lo mismo que ECLIPSE & $\begin{array}{l}\text { ECEPTUAR ant. EXCEPTUAR } \\
\text { (solo 1822) }\end{array}$ \\
EFETO ant. Lo mismo que EFECTO & $\begin{array}{l}\text { EGICIANO ant. Lo mismo que } \\
\text { EGIPCIANO }\end{array}$ \\
FAICIÓN ant. Lo mismo que FACCIÓN & EMENDA ant. Lo mismo que \\
(solo 1817) & ENMIENDA \\
FATOR ant. Lo mismo que FACTOR & FATORÍA ant. Lo mismo que \\
(FATORÍA) & FACTORIA (FATOR) \\
FATURA ant. Lo mismo que FACTURA & USUFRUTURARIO ant. Lo mismo \\
FATURÍA ant. Lo mismo que FAUTORÍA & que USUFRUCTUARIO \\
IMPERFICION ant. Lo mismo que & \\
IMPERFECCIÓN & \\
LACIVIOSO sin marca Lo mismo que & \\
LASCIVO & \\
\hline
\end{tabular}

Hay, por último, otros casos de cambios gráficos atribuibles a la variación en la pronunciación, a la igualación de los sonidos afectados, que reflejan alternancias en distintas posiciones: gelosía por celosía, ladrocinio por latrocinio, sagramento por sacramento o sagristía por sacristía, son eliminados del DRAE 1822. Claro que, al tiempo que suprimen estas formas, otras semejantes se mantienen: candidado por candidato, gamello por camello, gañivete ${ }^{77}$ por cañivete, hebrero por febrero, mastigar por masticar, o saludación por salutación ${ }^{78}$.

77 No remite a cañivete en DRAE 2014.

78 Se mantienen hasta el DRAE 2014, con cambio de marca de anticuado a poco usado, hecho que puede considerarse una reinterpretación o recuperación de la voz. 


\section{EL DICCIONARIO, FUENTE PARA LA HISTORIA DEL LÉXICO}

Lo expuesto hasta aquí pone de manifiesto la existencia de arcaísmos gráficos suprimidos y conservados a partir de la sexta edición del diccionario académico y las razones para ello: la supresión responde al deseo de actualizar el diccionario, de modernizarlo, en un momento, además, en que la concepción del diccionario no era ya la que determinó la reducción de Autoridades 1726-1739 desde 1780; la conservación, por el contrario, obedece al apego de la obra y de la corporación académicas a la tradición, de lo que resulta que los arcaísmos gráficos brindan la posibilidad de conocer distintos estadios de la evolución formal de una palabra, así como los efectos de cambios en la pronunciación. Precisamente, al registrar estas últimas formas, se destaca la función didáctica y normativa del diccionario, lo que favorece su mantenimiento para orientar en su uso.

No termina aquí, en la sexta edición, el interés por este tipo de formas, a pesar de que muchas fueran suprimidas, pues el mantenimiento de otras voces, con variación gráfica e, incluso, morfológica, sigue reclamando la atención de la Academia. Así lo manifiesta en ediciones posteriores a la examinada:

La Academia ha continuado suprimiendo las voces anticuadas que solo se diferencian de las corrientes en el aumento, disminucion ó alteracion de una o dos letras, y en particular varias que tenian al principio la redundancia de una $a$, conservándose sin embargo algunas para que no se olvide totalmente su uso en lo antiguo, como Atal, Abastar \&c. Con mas razón ha proseguido suprimiendo los vocablos que solo por viciosa pronunciacion se diferencian en algo de los propios y castizos (DRAE 1832: Prólogo $)^{79}$.

Y, como en esa y en otras posteriores, en la última edición, en que la atención a las variantes gráficas lleva a introducir un cambio que supone destacar la forma gráfica "no preferida", por poco usada, incorrecta, etc., si bien las desusadas se presentan como hasta ahora:

En ediciones anteriores [...] la variante preferida se erigía en lema exclusivo de un artículo con definición o definiciones por extenso (por ejemplo, sustancia), y la no preferida se definía por remisión a aquella

79 Se refiere a voces que califica como "voces desfiguradas", "escritas con mala ortografía" y "pronunciadas a la manera del ínfimo vulgo" (DRAE 1832: Prólogo). 
[...] Este procedimiento tenía, entre otros, el inconveniente de que la consulta exclusiva del artículo sustancia no daba noticia de la existencia de la variante. En esta edición la variante o variantes se enuncian dentro del paréntesis informativo que sigue al lema (que se corresponde con la variante principal), precedida de la palabra "también" abreviada: [...] sustancia (Tb. substancia) (DRAE 2014: XLIII-XLIV).

Es una manera de tener presente una variante, de informar de su existencia y de dar cuenta de su relación con aquella a la que sustituye, como hicieron las recogidas hasta la sexta edición y lo siguieron haciendo las que se mantuvieron o fueron más tarde recuperadas.

\section{REFERENCIAS BIBLIOGRÁFICAS}

Estudios

Alcoba, santiago. 2007. Ortografía y $D R A E$. Algunos hitos en la fijación léxica y ortográfica de las palabras. Español Actual 88: 11-42.

Alvar Ezquerra, Manuel. 2002. El Diccionario de la Academia en sus prólogos. En De antiguos y nuevos diccionarios del español, pp. 253-286. Madrid: Arco Libros.

Ariza, Manuel. 1999. Manual de fonología histórica del español. Madrid: Síntesis.

Azorín, Dolores. 2018. El léxico con marcación estilística. En Gloria Clavería y Margarita Freixas (coords.), pp. 427-458.

Barbolani, Cristina. ed. 1995. Juan de Valdés, Diálogo de la lengua. Madrid: Cátedra.

BlANCO, Ma Ángeles. 2018. El contexto del diccionario: los códigos académicos vigentes en 1817. En Gloria Clavería y Margarita Freixas (coords.), pp. 57-63.

CANo, Rafael. 1988 [2002]. El español a través de los tiempos. Madrid: Arco Libros.

Carriscondo, Francisco M. 2009. En los orígenes del método colegiado académico: el "Papel de reparos" al Diccionario (1731). Bulletin Hispanique 101: 109-140.

Castillo Carballo, Ma Auxiliadora. 2003. La macroestructura del diccionario. En Antonia M. Medina Guerra (coord.). Lexicografía española, pp. 79-101. Barcelona: Ariel.

Castillo Peña, Carmen. 1992. La definición sinonímica y los círculos viciosos. Boletín de la Real Academia Española 72: 463-566.

Clavería, Gloria. 1991. El latinismo en español. Bellaterra: Universidad Autónoma de Barcelona.

1995. El cambio de "o" a "u” en abundar y derivados. Moenia, Revista lucense de lingüística y literatura 1: 367-382.

2016. De vacunar a dictaminar: la lexicografía académica decimonónica y el neologismo. Madrid/Frankfurt: Iberoamericana/Vervuert.

2018. La quinta edición del Diccionario de la lengua castellana (1817) de la Real Academia Española al microscopio. En Gloria Clavería y Margarita Freixas (coords.), pp. $15-55$. 
Clavería, Gloria y Margarita Freixas. 2015. La quinta edición del Diccionario de la lengua castellana de la Real Academia Española (1817): el aumento de voces. En José Ma García Martín (ed.). Actas del IX Congreso Internacional de Historia de la Lengua Española, vol. II, pp. 1309-1326. Madrid/Frankfurt: Iberoamericana/Vervuert.

(coords.). 2018. El Diccionario de la Academia en el siglo XIX: la quinta edición (1817) al microscopio. Madrid: Arco Libros.

Clavería, Gloria et al. (2017). Historia interna del Diccionario de la Lengua Castellana de la Real Academia Española en el siglo XIX (1817-1852). En Ignacio Sariego et al. (ed.). El Diccionario en la encrucijada: de la sintaxis y la cultura al desafio digital, pp. 151-172. Santander: Escuela Universitaria de Turismo Altamira y Asociación Española de Lexicografía Hispánica.

Dworkin, Steven N. 2004. La transición léxica en el español bajomedieval. En Rafael Cano (coord.). Historia de la lengua española, pp. 643-656. Barcelona: Ariel.

Esteve, Abraham. 1982. Estudios de teoría ortográfica del español. Murcia: Universidad de Murcia.

Fernández Sevilla, Julio. 1974. Problemas de lexicografia actual. Bogotá: Instituto Caro y Cuervo.

Freixas, Margarita. 2016. Orígenes de la Ortografía de la RAE: primeras aportaciones de Bartolomé Alcázar (1715) y de Adrián Conink (h. 1716). Revista de Filología Española 96: 113-148.

Fries, Dagmar. 1989. Limpia, fija y da esplendor. La Real Academia Española ante el uso de la lengua (1713-1973). Madrid: SGEL.

García de la Concha, Víctor. 2014. La Real Academia Española. Vida e historia. Madrid: Espasa-Calpe.

García Santos, Juan Felipe. 2011. Las ortografías académicas del siglo XVIII (con una extensión hasta 1844). En José J. Gómez Asencio (dir.). El castellano y su codificación gramatical, vol. III: De 1700 a 1835, pp. 445-492. Burgos: Fundación Instituto Castellano y Leonés de la Lengua.

GonzÁLEZ OlLÉ, Fernando. 1992. Defensa y modernización del español: Salazar y Castro frente a la Academia Española. En Manuel Ariza et al. (ed.). Actas del II Congreso Internacional de Historia de la Lengua Española, pp. 165-197. Madrid: Pabellón de España.

HAENSCH, Günther. 1985. La selección del material léxico para diccionarios descriptivos. En Philologica hispaniensia in honorem Manuel Alvar, II, pp. 227-254. Madrid: Gredos.

HaEnsch, Günther et al. 1982. La lexicografía. De la lingüística teórica a la lexicografía práctica. Madrid: Gredos.

Haensch, Günther y Carlos Omeñaca. 2002. Los diccionarios del español en el umbral del siglo XXI. Salamanca: Universidad de Salamanca.

JiMÉNEZ Ríos, ENRIQUE. 2001. Variación léxica y diccionario: los arcaísmos en el diccionario de la Academia. Madrid/Frankfurt: Iberoamericana/Vervuert.

2018. El léxico con marcación diacrónica. En Gloria Clavería y Margarita Freixas (coords.), pp. 399-426.

LAPESA, RAFAel. 1986. Historia de la lengua española. Madrid: Gredos, $9^{\text {a }}$ edición.

LÁZARo, FernANDo. 1972 [1980]. El primer diccionario de la Academia. Estudios de lingüística, pp. 83-148. Barcelona: Crítica.

Martínez Alcalde, Ma José. 2012. Ortografía. En Antonio Zamorano (ed.). Reflexión lingüistica y lengua en la España del XIX. Marcos, panoramas y nuevas aportaciones, pp. 95-115. München: Lincom Europa.

Martínez de Sousa, José. 1991. Reforma de la ortografía española. Madrid: Visor Libros.

MENÉNDeZ PidAl, RAmón. 1987. Manual de gramática histórica española. Madrid: EspasaCalpe, $19^{\text {a }}$ edición. 
MuÑoz, LaURA. 2018. La sinonimia y las remisiones. En Gloria Clavería y Margarita Freixas (coords.), pp. 203-221.

Quilis Merín, Mercedes. 2009. Diccionario y normas ortográficas: panorama y aplicaciones en la lexicografía española de los siglos XVIII al XIX. En Elena de Miguel et al. (eds.). Fronteras de un diccionario. Las palabras en movimiento, pp. 83-120. San Millán de la Cogolla: Cilengua.

Pascual, José Antonio. 1974. La traducción de La Divina Comedia atribuida a D. Enrique de Aragón. Estudio y edición del Infierno. Salamanca: Ediciones Universidad de Salamanca.

Rosenblat, Ángel. 1951. Las ideas ortográficas de Bello. En Andrés Bello, Obras completas, tomo V: Estudios gramaticales, pp. IX-CXXXVIII. Caracas: Ediciones del Ministerio de Educación.

Sánchez-Prieto, Pedro. 1998. Cómo editar los textos medievales. Criterios para su presentación gráfica. Madrid: Arco Libros.

2002. Sobre una supuesta evolución circular en español: CAUSA $>$ CABSA $>$ CAUSA. En Carmen Saralegui Platero y Manuel Casado Velarde (eds.). Pulchre, bene, recte. Estudios en homenaje al Prof. Fernando González Ollé, pp. 1287-1310. Pamplona: ENUSA.

Seco, Manuel. 1993 [2003]. La otra voz de la Academia Española: notas sobre el Diccionario manual. En Estudios de lexicografia, pp. 337-350. Madrid: Gredos.

Terreros, Esteban DE. 1786-1793. Diccionario castellano con las voces de artes y ciencias. Edición facsímil, Madrid: Arco Libros, 1987.

TeRrón, NATAlia. 2018. La regularización ortográfica. En Gloria Clavería y Margarita Freixas (coords.), pp. 67-91.

\section{FUENTES}

Autoridades 1726-1739 = Real Academia Española. 1726-1739. Diccionario de Autoridades . Edición facsímil. Madrid: Gredos.

Autoridades $1770=$ Real Academia Española. 1770. Diccionario de la lengua castellana . Madrid: Joachín Ibarra, tomo A-B. Consultado en NTLLE.

$C D H=$ Instituto de Investigación Rafael Lapesa de la Real Academia Española. 2013. Corpus del Nuevo diccionario histórico $(\mathrm{CDH})$ [en línea]. <http://web.frl.es/CNDHE > [Consulta: enero-marzo 2017].

CORDE $=$ Real Academia Española. Corpus diacrónico del español. Banco de datos en línea. $<$ http://www.rae.es> [consulta: enero-marzo 2017].

Discurso $=$ Real Academia Española. 1726. Discurso proemial de la orthographia. En Diccionario de Autoridades, edición facsímil, pp. LXVII-LXVIII. Madrid: Gredos.

DECH = Corominas, Joan y Pascual, José A. 1980-1991. Diccionario crítico etimológico castellano e hispánico. Madrid: Gredos.

DH 1933 = Real Academia Española. 1933. Diccionario histórico de la lengua española . Tomo I-A, Madrid: Imprenta de Librería y Casa Editorial Hernando.

DRAE 1780 = Real Academia Española. 1780. Diccionario de la lengua castellana, reducido a un solo tomo para su más fácil uso. Madrid: Joaquín Ibarra.

DRAE 1803 = Real Academia Española. 1803. Diccionario de la lengua castellana, reducido a un solo tomo para su más fácil uso, cuarta edición. Madrid: Viuda de don Joaquín Ibarra.

DRAE 1817 = Real Academia Española. 1817. Diccionario de la lengua castellana, quinta edición. Madrid: Imprenta Real.

DRAE 1822 = Real Academia Española. 1822. Diccionario de la lengua castellana, sexta edición. Madrid: Imprenta Nacional. 
DRAE 1832 = Real Academia Española. 1832. Diccionario de la lengua castellana, séptima edición. Madrid: Imprenta Real.

DRAE 2014 = Real Academia Española /Asociación de Academias de la Lengua Española. 2014. Diccionario de la lengua española, vigesimotercera edición. Barcelona: Espasa.

ORAE 1815 = Real Academia Española. 1815. Ortografía de la lengua castellana. Octava edición notablemente reformada y corregida. Madrid: Imprenta Real.

ORAE 1820 = Real Academia Española. 1820. Ortografía de la lengua castellana. Novena edición notablemente reformada y corregida. Madrid: Imprenta Nacional.

ORAE 2010 = Real Academia Española /Asociación de Academias de la Lengua Española. 2010. Ortografía de la lengua española. Madrid: Espasa. 